\title{
FBL2 Regulates Amyloid Precursor Protein (APP) Metabolism by Promoting Ubiquitination-Dependent APP Degradation and Inhibition of APP Endocytosis
}

\author{
Tomomichi Watanabe, ${ }^{1}$ Yukiko Hikichi, ${ }^{2}$ Antje Willuweit, ${ }^{3}$ Yasushi Shintani, ${ }^{4}$ and Takashi Horiguchi ${ }^{4}$ \\ ${ }^{1}$ CNS Drug Discovery Unit, ${ }^{2}$ Oncology Drug Discovery Unit, ${ }^{3}$ Evotec Neurosciences, 8008 Zurich, Switzerland, and ${ }^{4}$ Biology Research Laboratories, \\ Pharmaceutical Research Division, Takeda Pharmaceutical, Fujisawa, Kanagawa, 251-8555, Japan
}

\begin{abstract}
The ubiquitin-proteasome pathway is a major protein degradation pathway whose dysfunction is now widely accepted as a cause of neurodegenerative diseases, including Alzheimer's disease. Here we demonstrate that the F-box and leucine rich repeat protein2 (FBL2), a component of the E3 ubiquitin ligase complex, regulates amyloid precursor protein (APP) metabolism through APP ubiquitination. FBL2 overexpression decreased the amount of secreted amyloid $\beta(\mathrm{A} \beta)$ peptides and sAPP $\beta$, whereas FBL2 mRNA knockdown by siRNA increased these levels. FBL2 overexpression also decreased the amount of intracellular A $\beta$ in Neuro2a cells stably expressing APP with Swedish mutation. FBL2 bound with APP specifically at its C-terminal fragment (CTF), which promoted APP/CTF ubiquitination. FBL2 overexpression also accelerated APP proteasome-dependent degradation and decreased APP protein localization in lipid rafts by inhibiting endocytosis. These effects were not observed in an F-box-deleted FBL2 mutant that does not participate in the E3 ubiquitin ligase complex. Furthermore, a reduced insoluble $\mathrm{A} \beta$ and $\mathrm{A} \beta$ plaque burden was observed in the hippocampus of 7-month-old FBL2 transgenic mice crossed with double-transgenic mice harboring APPswe and PS1 ${ }_{\mathrm{M} 146 \mathrm{~V}}$ transgenes. These findings indicate that FBL2 is a novel and dual regulator of APP metabolism through FBL2-dependent ubiquitination of APP.
\end{abstract}

\section{Introduction}

Alzheimer's disease (AD) is a progressive and fatal neurodegenerative disorder characterized by the deposition of extracellular amyloid $\beta(\mathrm{A} \beta)$ plaques and formation of intracellular neurofibrillary tangles (NFTs) in the CNS (Terry et al., 1981; Tanzi and Bertram, 2005; Haass and Selko, 2007). Genetic studies of familial $\mathrm{AD}$ cases identified mutations associated with the disease that result in increased production of $\mathrm{A} \beta$ peptides, especially C-terminal extended forms $\left(A \beta_{42}\right)$ that aggregate more readily (Haass et al., 1995; Selkoe, 1998). These observations, together with cumulative evidence of $A \beta$ on neuronal/neural toxicity, support a key role for $\mathrm{A} \beta$ in $\mathrm{AD}$ pathophysiology. Although most therapeutic strategies have focused on developing $A \beta$-lowering drugs, to date these approaches have not been successful.

The ubiquitin-proteasome pathway is essential for preventing accumulation of abnormal intracellular proteins (Hershko et al.,

\footnotetext{
Received Nov. 9, 2011; revised Dec. 26, 2011; accepted Jan. 1, 2012.

Author contributions: T.W. designed research; T.W. and Y.H. performed research; A.W. contributed unpublished reagents/analytic tools; T.W., Y.S., and T.H. analyzed data; T.W. wrote the paper.

We thank Drs. Takeshi Iwatsubo and Taisuke Tomita (Tokyo University, Tokyo, Japan) for helpful advice. We also thank Dr. Hiroyuki Miyoshi (RIKEN BioResource Center, Ibaraki, Japan) for providing and helpful advice for lentiviral vector system. We are grateful to Hideaki Nagaya, Takeo Wada, Keisuke Hirai, and Masaomi Miyamoto for their encouragement and helpful advice.

Correspondence should be addressed to Tomomichi Watanabe, CNS Drug Discovery Unit, Pharmaceutical Research Division, Takeda Pharmaceutical Co. Ltd., 26-1, Muraoka-higashi 2-chome, Fujisawa, Kanagawa, 251-8555, Japan. E-mail: Watanabe_Tomomichi@takeda.co.jp.

A. Willuweit's present address: Institute of Neuroscience and Medicine, Froschungszentrum Jülich, 52425 Jülich, Germany.

DOI:10.1523/JNEUROSCI.5659-11.2012

Copyright $\odot 2012$ the authors $\quad 0270-6474 / 12 / 323352-14 \$ 15.00 / 0$
}

2000; Bedford et al., 2011). In the CNS, protein degradation by the ubiquitin-proteasome pathway is critical for breaking down and removing damaged or misfolded cellular proteins (AlvesRodrigues et al., 1998; Chen et al., 2006; Ortega et al., 2010). Recent studies indicated that impairment of the ubiquitin-proteasome pathway causes neurodegenerative diseases, such as $\mathrm{AD}$ and Parkinson's disease. Mutant ubiquitin was reported to be detectable in the brains of $\mathrm{AD}$ patients and was able to inhibit proteasome activity (van Leeuwen et al., 1998; Lam et al., 2000; López Salon et al,. 2000; Tan et al., 2007). Ubiquitinated proteins, including NFTs, have also been found in several neurodegenerative diseases (Perry et al., 1987; Ciechanover and Brundin, 2003). Furthermore, mutations in the parkin gene were discovered in autosomal recessive juvenile parkinsonism (Kitada et al., 1998), with Parkin shown to be an E3 ubiquitin ligase (Shimura et al., 2000). Together, this evidence suggests that the ubiquitin-proteasome pathway is one of the most promising targets for treating neurodegenerative diseases, including $\mathrm{AD}$.

Ubiquitination is a sequential enzymatic reaction composed of ubiquitin-activating enzyme (E1), ubiquitin-conjugating enzyme (E2), and ubiquitin-protein ligase (E3). The E3 ubiquitinprotein ligases play an important role in the ubiquitination reaction because they mediate target protein recognition. It was reported that expression levels of the F-box and leucine rich repeat protein2 (FBL2), a component of the SCF (Skp1-Cullin1F-box protein) E3 ubiquitin ligase complex, decreased in the brains of AD patients (Blalock et al., 2004). However, the function and specific substrate for FBL2 remains unclear. Our current study demonstrates that FBL2 impacts amyloid precursor protein 
A

F-box region

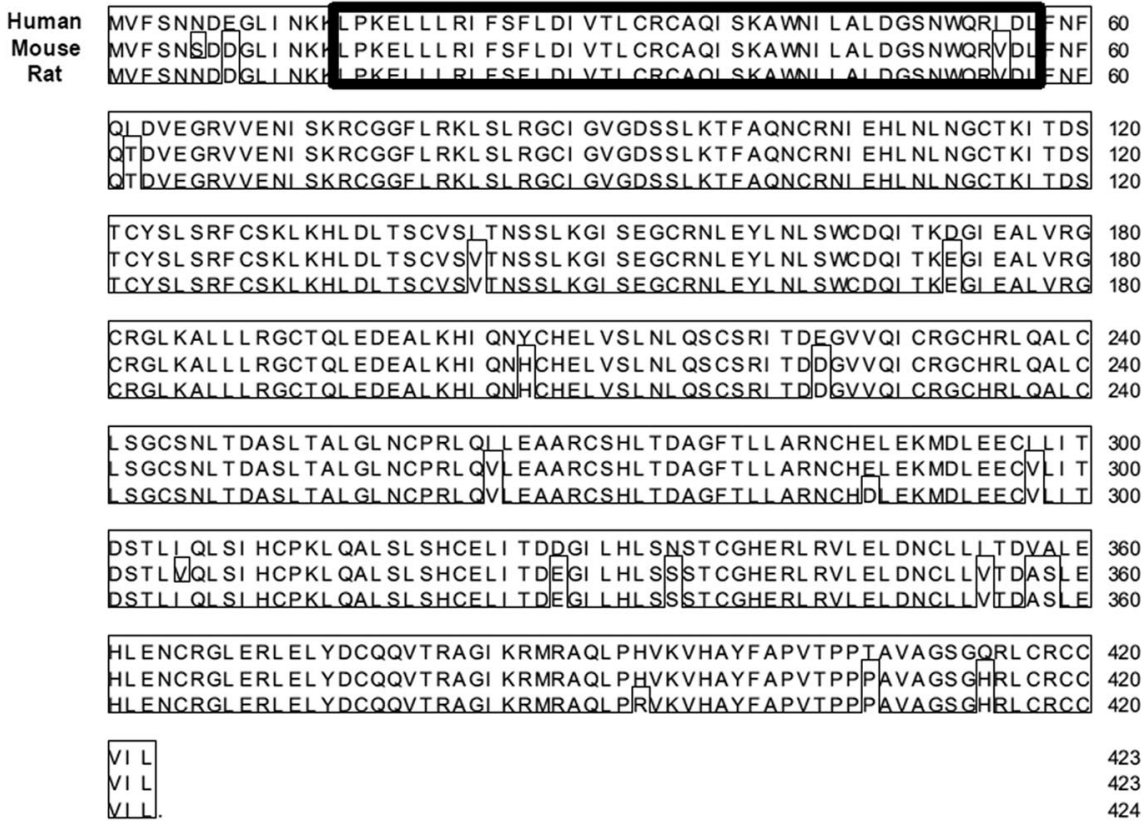

B

wtFBL2

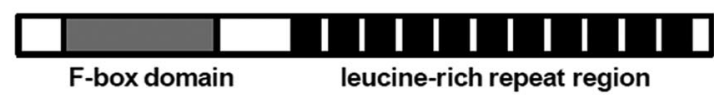

Fbox-deleted FBL2

(dFbox)

$\square$ | | | | | | | | |

leucine-rich repeat region

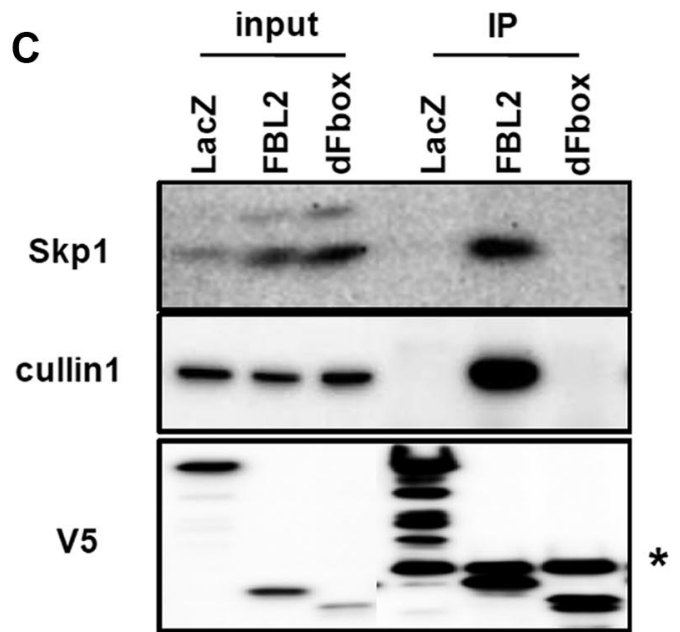

D

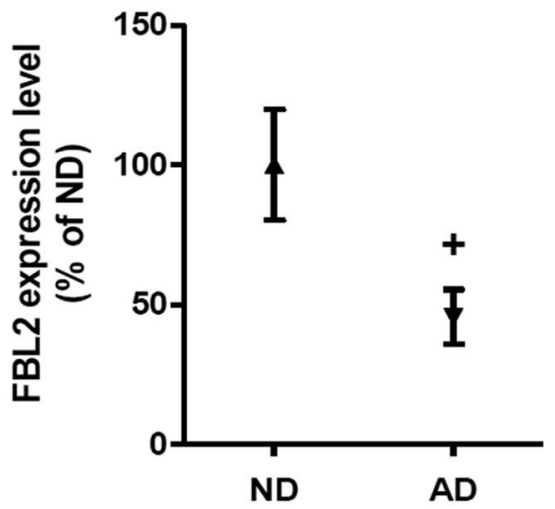

Figure 1. FBL2 is a component of the SCF ubiquitin ligase complex. $A$, Multiple alignments of human, mouse, and rat FBL2 protein sequences. The F-box region is enclosed by a red line. $B$, Diagram of wild-type FBL2 with F-box motif and leucine rich repeat region and F-box deleted FBL2 (dFbox). C, Lysates from HEK293 cells transfected with skp1 and cullin 1 together with V5-tagged LacZ (control) or V5-tagged FBL2 were immunoprecipitated (IP) with anti-V5 antibody and protein G Sepharose. Immunoblot analyses were performed with anti-Skp1, anti-Cullin1, or anti-V5 antibodies. Asterisk indicates IgG band. $\boldsymbol{D}$, Quantitative PCR analysis of FBL2 mRNA expression levels in cortices of AD (denoted as AD, $n=17$ ) or nondemented (denoted as ND, $n=16$ ) individuals. The expression level of FBL2 was normalized to the mean average value of a set of five reference genes (cyclophilin B, ribosomal protein $59, \beta$-actin, GAPDH, and transferrin receptor) using $C_{\mathrm{t}}$ value. Means \pm SE percentages of the relative ratio of FBL2 mRNA levels in nondemented individuals are indicated. Statistical analysis was performed by Welch's test, ${ }^{+} p \leq 0.05$.

(APP) metabolism by interacting with APP to modulate APP ubiquitination.

\section{Materials and Methods}

\section{Antibodies}

The APP specific anti-APP antibody CT695 recognizes APP amino acids 673-695 and was purchased from Zymed. Anti-ubiquitin antibody
P4D1, anti-S-phase-kinase-associated protein 2 (Skp1) antibody, anti- $\beta$ secretase1 (BACE1), anti-Cullin1 antibody, and anti-calreticulin antibody were purchased from Santa Cruz Biotechnology. Anti-V5 antibody was purchased from Invitrogen. Anti-flotillin and anti-GM130 antibodies were purchased from BD Biosciences Transduction Laboratories. Anti-neprilysin (NEP) antibody was purchased from Novocastra. Antiinsulin-degrading enzyme (IDE) was purchased from Calbiochem. 
Quantitative RT-PCR

Human brain samples. Brain tissue $<20$ h postmortem was obtained from patients with symptomatic diagnosis and histopathologically confirmed $\mathrm{AD}$; tissue from age-matched control subjects was obtained from the Netherlands Brain Bank.

Quantitative real-time PCR. Total RNA was extracted from frozen postmortem brain tissue using the RNeasy kit (Qiagen) according to the protocol of the manufacturer and transcribed into cDNA with the Sensiscript RT Kit (Qiagen). Quantitative real-time PCR was performed in a volume of $20 \mu \mathrm{l}$ containing LightCycler-FastStart DNA Master SYBR Green I mix, $0.5 \mu \mathrm{M}$ primers, $2 \mu \mathrm{l}$ of a cDNA dilution series $(20,10,5,1$, and $0.5 \mathrm{ng}$ of human total brain cDNA; Clontech), and additional 3 and $1 \mathrm{~mm} \mathrm{MgCl}_{2}$ for FBL2 and cyclophilin B, respectively. Samples were amplified with each specific primer pair for FBL2 (5'-TACTGGGTGGAGCAGGGTCTT-3' and 5'-GGTCCCTGGAGGTGTATATGACA-3') and five reference genes: (1) cyclophilin B (5'-ACTGAAGCACTACGGGCCTG- ${ }^{\prime}$ ' and 5'-AGCCGTTGGTGTCTTTGCC-3'); (2) ribosomal protein S9 (5'-GGTCAAATTTACCC TGGCCA- ${ }^{\prime}$ and $5^{\prime}$-TCTCATCAAGCGTCAG CAGTTC- $3^{\prime}$ ); (3) $\beta$-actin ( $5^{\prime}$-TGGAACGGTG AAGGTGACA- $3^{\prime}$ and $5^{\prime}$-GGCAAGGGACTT CCTGTAA-3'); (4) GAPDH (5'-GC TAAGC AGTTGGTGGTGCAG- $3^{\prime}$ and $5^{\prime}$-GC TAA GCAGTTGGTGGTGCAG-3'); and (5) transferrin receptor TRR (5'-GTCG CTGGTCAGTTCGTGATT-3' and 5' -AGCAG TT GGCTGTTGTACCTCTC-3') using Light Cycler-DNA-Master-SYBR-Green mix (Roche), as well as $2 \mu \mathrm{l}$ of cDNA in separate reactions. The PCR parameters were $95^{\circ} \mathrm{C}$ for $10 \mathrm{~min}$ and then 50 cycles of the following: $95^{\circ} \mathrm{C}, 1 \mathrm{~s} ; 56^{\circ} \mathrm{C}$, $5 \mathrm{~s} ; 72^{\circ} \mathrm{C}, 5 \mathrm{~s}$. For melting curve determination, the following was used: $95^{\circ} \mathrm{C}, 1 \mathrm{~s}\left(4.4^{\circ} \mathrm{C} / \mathrm{s}\right)$; $65^{\circ} \mathrm{C}, 15 \mathrm{~s}\left(2.2^{\circ} \mathrm{C} / \mathrm{s}\right) ; 95^{\circ} \mathrm{C}$. Samples were analyzed in triplicate for each primer pair. The $\mathrm{C}_{t}$ parameter was derived for each cDNA sample and primer pair. The expression level of FBL2 was normalized to the mean average value of the five reference gene set.

\section{Cell culture}

Cerebral cortical neurons in primary culture were prepared from fetal mice at $14 \mathrm{~d}$ of gestation using a neural cell dispersion kit (Sumilon) according to the protocol of the manufacturer. The dissociated cell suspensions were plated at a density of $2 \times 10^{5}$ cells per well in poly-Llysine-coated 24-well plates (Sumilon) in Neurobasal medium (Invitrogen) supplemented with $2 \%$ B27 (Invitrogen) and $0.5 \mathrm{~mm}$ glu-

tamine (Invitrogen). Human embryonic kidney 293 (HEK293) and IMR-32 human neuroblastoma cells were purchased from the American Type Culture Collection. HEK293 cells were passaged in DMEM (Invitrogen) supplemented with $10 \%$ fetal bovine serum (FBS). IMR-32 cells were passaged in minimum essential medium (Eagle) (Invitrogen) supplemented with $10 \%$ FBS, $0.1 \mathrm{~mm}$ non-essential amino acids, and $1 \mathrm{~mm}$ sodium pyruvate (Invitrogen).

\section{Cloning}

Human FBL2 cDNA (GenBank accession number NM_012157.2), human Skp1 (GenBank accession number NM_170679.1), and human $0.05,{ }^{* *} p<0.01$, Student's $t$ test.

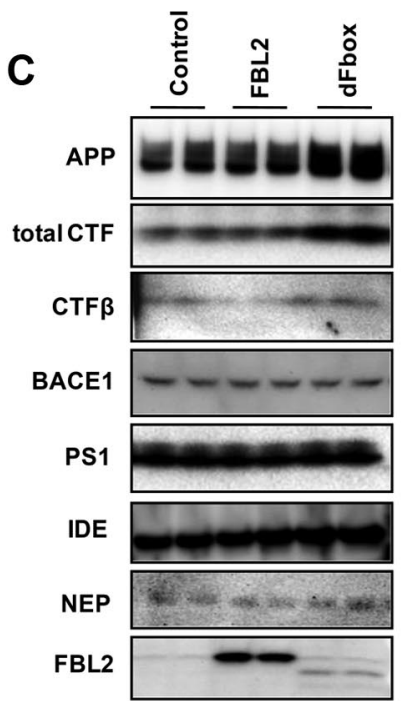

\section{B}

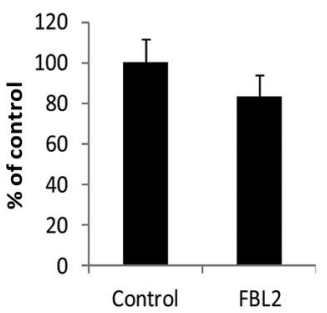

$\mathbf{E}$

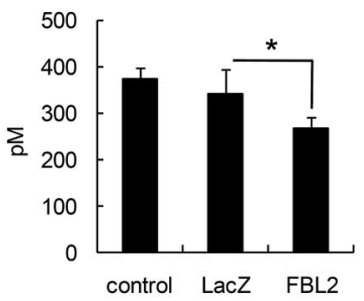

SAPP $\beta$

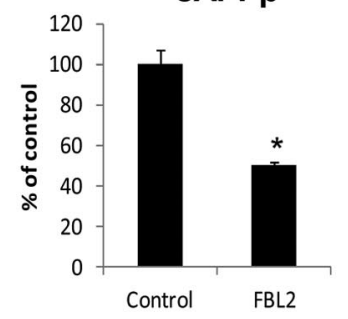

D

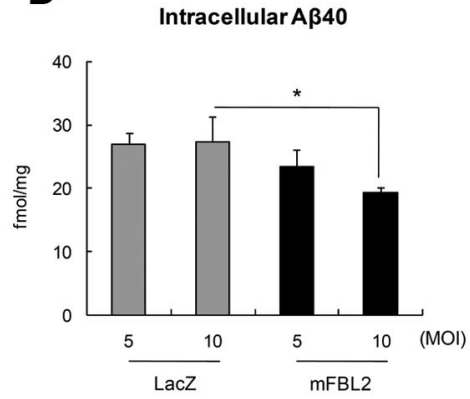

WST8

Figure 2. Suppression of $A \beta$ secretion by FBL2 overexpression. HEK293 cells were cotransfected with APP and FBL2 expression vectors. The medium was changed two times $18 \mathrm{~h}$ after transfection, and the amount of $A \beta(\boldsymbol{A}), \operatorname{sAPP} \alpha$, and $\operatorname{APP} \beta(\boldsymbol{B})$ secreted in the medium was measured by sandwich ELISA $18 \mathrm{~h}$ after the medium change. $\boldsymbol{C}$, Transfected cell lysates were subjected to immunoblotting with each antibody. $\boldsymbol{D}$, Effect of FBL2 on intracellular A $\beta$ in swAPP-Neuro2a cells. LacZ-expressing lentivirus or mouse FBL2-expressing lentivirus was transfected to swAPP-Neuro2a cells. RIPA soluble fractions were isolated $3 \mathrm{~d}$ after transfection, and intracellular $A \beta_{40}$ was measured by sandwich ELISA normalized for protein concentration. $\boldsymbol{E}$, Effect of FBL2 on A $\beta$ secretion in mouse cortical neurons. Mouse cortical neurons (DIV8) were transfected with LacZ or mouse FBL2-expressing lentivirus (MOI of 5). Control represents nontransfected cortical neurons. Four days after lentivirus transfection, the medium was changed and the transfected cells were further incubated for $3 \mathrm{~d}$. The amount of $A \beta$ secreted in the medium was measured by sandwich ELISA. Mitochondrial respiratory activity was measured by WST8 (2-(2-methoxy-4nitrophenyl)-3-(4-nitrophenyl)-5-(2,4-disulfophenyl)-2H-tetrazolium, monosodium salt) assay. Means \pm SD percentages of the relative ratio of secreted $A \beta$, sAPP, and ATP levels in LacZ-transfected cells (control) are indicated $(\boldsymbol{A}, \boldsymbol{B}) .{ }^{++}{ }^{+} p<0.001$, Dunnett's test; ${ }^{*} p<$

Cullin1 (GenBank accession number NM_003592.2) were amplified by PCR from quick clone human whole-brain cDNA (Clontech). The cDNAs were cloned into the pcDNA3.1/V5-His TOPO vector (Invitrogen). Mouse FBL2 cDNA (GenBank accession number NM_178624.2) was amplified by PCR from mouse brain first-strand cDNA in mouse multiple tissue cDNA panel I (BD Bioscience) and cloned into the pcDNA3.2/V5/GW/D-TOPO vector (Invitrogen).

Quantitation of $A \beta$ and $S A P P$ by ELISA

The day before transfection, HEK293 cells were plated in type I collagencoated 48 -well plates (Iwaki) at $4.2 \times 10^{4}$ cells per well density, and the 
A

$A \beta 40$

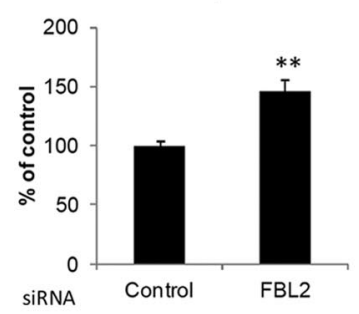

SAPP $\alpha$

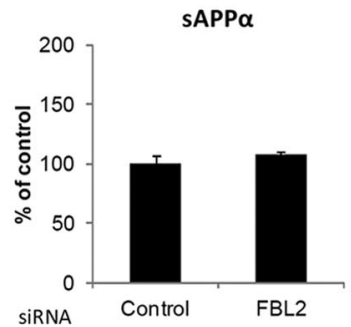

B

$A \beta 42$

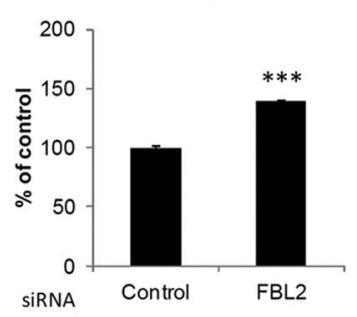

SAPP $\beta$

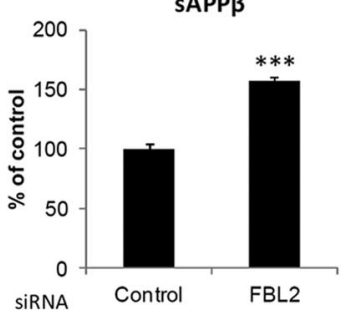

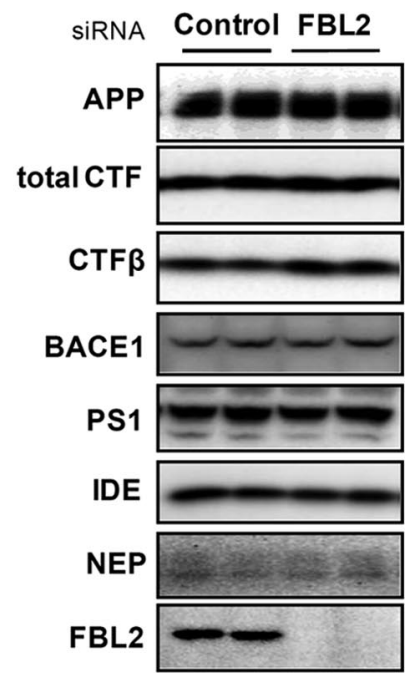

Figure 3. Upregulation of $A \beta$ secretion by FBL2 knockdown using siRNA in swAPP-Neuro2a cells. Control siRNA or human FBL2 siRNA was transfected to swAPP-Neuro2a cells. Twenty-four hours after transfection, the medium was changed and the transfected cells were further incubated for $24 \mathrm{~h}$. Secreted $A \beta$ and sAPP levels were measured by sandwich ELISA $(A)$. $\boldsymbol{B}$, Transfected cell lysates were subjected to immunoblotting with each antibody. Means \pm SD percentages of the relative ratio of secreted $A \beta$ and sAPP levels in control siRNA-treated cells are indicated. ${ }^{* *} p<0.01,{ }^{* * *} p<0.001$, Student's $t$ test.

cells were cultured for $18 \mathrm{~h}$. Transfection with a total of $0.7 \mu \mathrm{g}$ of plasmids $(0.35 \mu \mathrm{g}$ of swAPP plasmid and $0.35 \mu \mathrm{g}$ of wild-type hFBL2, deletion mutant hFBL2, or GFP plasmid) was performed using Lipofectamine2000 (Invitrogen) according to the instructions of the manufacturer. Eighteen hours after transfection, the medium was changed once, and the cells were further cultured for $18 \mathrm{~h}$. The amount of $\mathrm{A} \beta_{40}$ and $\mathrm{A} \beta_{42}$ in conditioned media was measured by sandwich ELISA (Suzuki et al., 1994). BNT-77 (A $\left.\beta_{11-28}\right)$ was used as the capture antibody, and either horseradish peroxidase-coupled BA-27 or BC-05 was used as the detector antibody for $\mathrm{A} \beta_{40}$ or $\mathrm{A} \beta_{42}$, respectively. $\operatorname{sAPP} \alpha$ and $\operatorname{sAPP} \beta$ were measured with the human $\operatorname{sAPP} \alpha$ (highly sensitive) assay kit (ImmunoBiological Laboratories) and human $\mathrm{sAPP} \beta$-sw (highly sensitive) assay kit (Immuno-Biological Laboratories), respectively.

\section{siRNA treatment}

The day before transfection, swAPP-Neuro2a cells (kindly provided by Prof. Iwatsubo, Tokyo University, Tokyo, Japan) were plated in 48-well plates (Iwaki) at a density of $2.8 \times 10^{5}$ cells per well, and the cells were cultured for $18 \mathrm{~h}$. The growth medium was removed, and Accell siRNA delivery media containing $1 \mu \mathrm{M}$ Accell Non-Targeting Pool siRNA (control) or Accell SMARTpool Mouse FBXL2 siRNA (Thermo Fisher Scientific) was added to the cells. Eighteen hours after treatment with siRNA, the culture medium was changed, and the transfected cells were further incubated for $18 \mathrm{~h}$. The amount of $\mathrm{A} \beta$ and sAPP in the medium was measured by ELISA.

\section{Preparation of lentivirus and transfection of primary mouse} cortical neurons

HIV-1-based lentiviral particles were generated by transient transfection of HEK293 cells with three plasmids: (1) the packaging construct ( $\mathrm{pCAG}-\mathrm{HIVgp}$ vector), in which all accessory genes (vif, vpr, vpu, and nef) and regulatory genes (tat and rev) were deleted; (2) the VSV-G- and Rev-expressing construct (pCMV-VSV-G-RSV-Rev vector); and (3) the self-inactivating lentiviral vector construct cloned with mouse FBL2 cDNA or LacZ cDNA (CSII-CMV-MCS vector) (all vectors were generous gifts from Dr. Miyoshi, RIKEN BioResource Center, Ibaraki, Japan). For poly-L-lysine coated $10 \mathrm{~cm}$ dishes, $17 \mu \mathrm{g}$ of CSII-CMV-MCS vector cloned mFBL2 or LacZ, $10 \mu \mathrm{g}$ of pCAG-HIVgp, and $10 \mu \mathrm{g}$ of pCMVVSV-G-RSV-Rev were used. High titer stocks were obtained by ultra- centrifugation at $50,000 \times g$ for $2 \mathrm{~h}$ at $20^{\circ} \mathrm{C}$. The stocks were titrated and normalized for the p24 antigen, as determined by ELISA (RETROTEK). Mouse FBL2-expressing lentivirus [multiplicity of infection (MOI) of 5] was transfected to mouse cortical neurons (DIV8). Four days after transfection, the culture medium was changed, and the transfected cells were further incubated for $3 \mathrm{~d}$. The amount of $\mathrm{A} \beta$ in the medium was measured by ELISA.

\section{Measurement of intracellular $A \beta$}

swAPP-Neuro2a cells were lysed with ice-cold RIPA buffer $(0.5 \%$ sodium deoxycholate, $0.1 \%$ SDS, $1 \%$ NP-40, 5 mm EDTA, 50 mm Tris-HCl, $150 \mathrm{~mm} \mathrm{NaCl}, 1 \mathrm{~mm} \beta$-mercaptoethanol $(\beta \mathrm{ME})$, and protease inhibitor cocktail) by sonication. The cell lysates were ultracentrifuged at $87,000 \times g$ for $20 \mathrm{~min}$ at $4^{\circ} \mathrm{C}$, and the supernatant was subjected to ELISA.

\section{Immunoprecipitation}

Transfection of various constructs into HEK293 cells was performed using Lipofectamine2000 (Invitrogen) according to the protocol of the manufacturer. Eighteen hours after transfection, $20 \mu \mathrm{M}$ proteasome inhibitor MG132 (carbobenzoxy-L-leucyl-L-leucyl-Lleucinal) (Calbiochem) was added to the transfected cells and incubated for $5 \mathrm{~h}$. The transfected cells cultured in collagen type I-coated $10 \mathrm{~cm}$ dishes were lysed with ice-cold lysis buffer (1\% Triton X-100, $50 \mathrm{~mm}$ Tris-HCl, $150 \mathrm{~mm} \mathrm{NaCl,} 1 \mathrm{~mm}$ $\beta \mathrm{ME}$, protease inhibitor cocktail, and $20 \mu \mathrm{M}$ MG132) by sonication. The lysate was centrifuged at $15,000 \times g$ for $15 \mathrm{~min}$ at $4^{\circ} \mathrm{C}$. For immunoprecipitation of V5-tagged hFBL2 or APP, supernatant fractions were incubated with protein G Sepharose (Zymed) and anti-V5 monoclonal antibody (Invitrogen) or anti-APP polyclonal antibody (CT695: Zymed) at $4^{\circ} \mathrm{C}$ for $18 \mathrm{~h}$, and the precipitated beads were washed three times with lysis buffer and then boiled in Tris-SDS- $\beta$ ME-sample buffer (Daiichi Pure Chemicals) at $95^{\circ} \mathrm{C}$ for $5 \mathrm{~min}$. The proteins were separated with a $4-20 \%$ Tris- $\mathrm{HCl}$ acrylamide gel (Daiichi Pure Chemicals) and transferred to polyvinyldiene difluoride membranes. The membranes were blocked with $5 \%$ skim milk in TBS-T buffer (50 mm Tris- $\mathrm{HCl}, 150 \mathrm{~mm}$ $\mathrm{NaCl}$, and $0.1 \%$ Tween 20 ) and probed with each antibody. The membrane was incubated with secondary antibody coupled with HRP. HRP activity was visualized using the ECL system (GE Healthcare).

\section{In vitro ubiquitination assay}

For expression of recombinant proteins, hFBL2 cDNA was subcloned into the pET28a vector (Novagen) to construct a plasmid expressing hFBL2 with an N-terminal six-histidine (His) tag. hSkp1 and hCullin1 were subcloned into the pET21b expression vector. Recombinant hFBL2, hSkp1, and hCullin1 were expressed in Escherichia coli BL21(DE3) by induction with isopropyl- $\beta$-D-thiogalactopyranoside. His-tagged FBL2, hSkp1, and hCullin1 complexes were affinity purified using Ni-NTA His-Bind Resin (Novagen) according to the protocol of the manufacturer. APP for substrate was immunoprecipitated with protein G Sepharose (Zymed) and anti-APP polyclonal antibody (CT695; Zymed) from APP-transfected HEK293 cell lysates. After an in vitro ubiquitination assay using the Fraction II Reticulocyte Conjugation kit (Boston Biochem) according to the protocol of the manufacturer, immunoprecipitated APP fractions were washed three times and subjected to immunoblotting analysis using the anti-ubiquitin antibody P4D1.

\section{Subcellular fractionation}

Cerebral hemispheres isolated from 10-week-old ICR mice were homogenized with homogenization buffer $(20 \mathrm{~mm}$ Tris-HCl, pH 7.5, $1 \mathrm{~mm}$ EDTA, and $250 \mathrm{~mm}$ sucrose) plus a protease inhibitor cocktail (Roche) using a Dounce homogenizer. A post-nuclear supernatant was centri- 


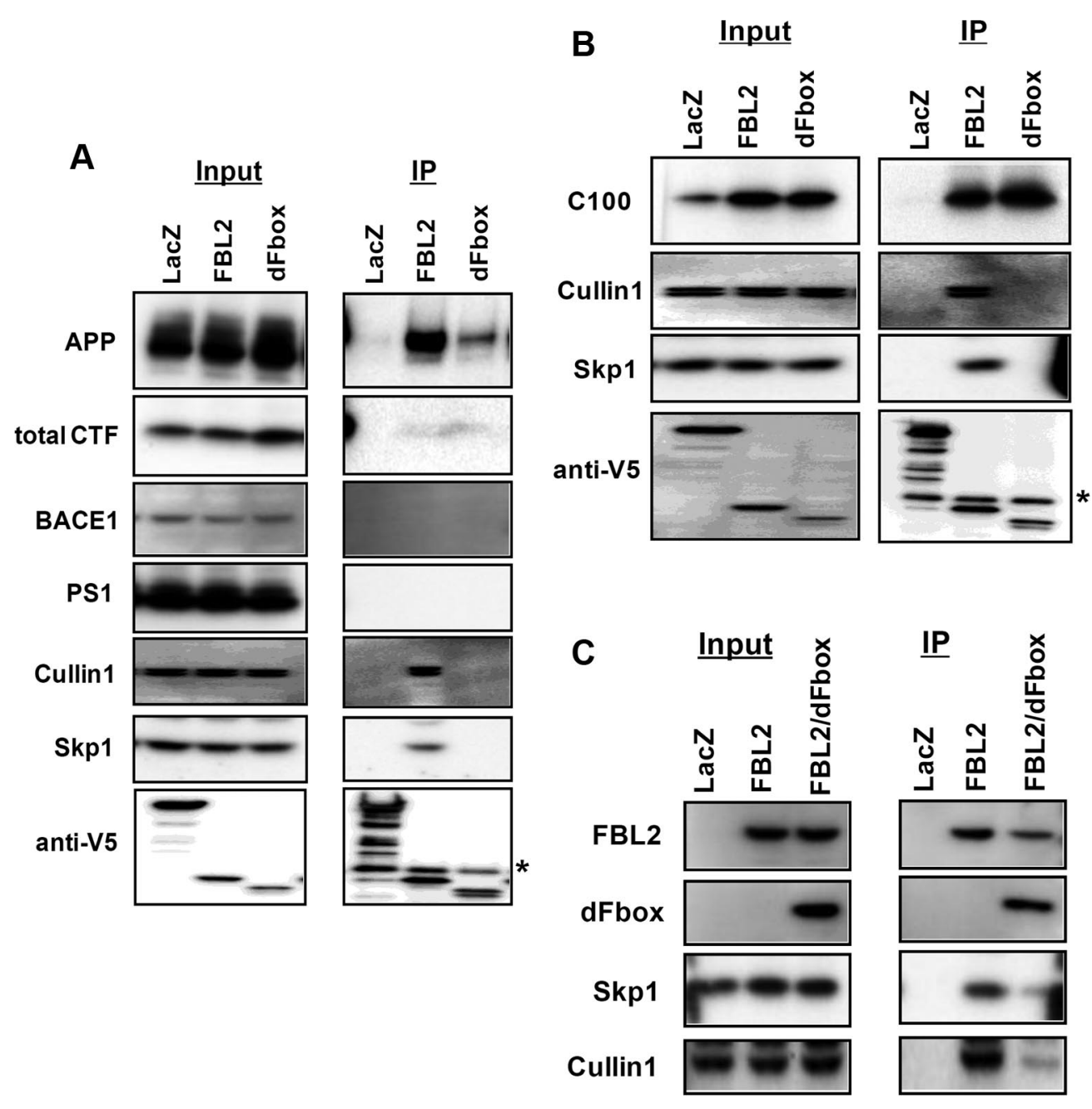

Figure 4. Interaction of FBL2 with APP and CTF. HEK293 cells were cotransfected with V5-tagged LacZ (control), V5-tagged FBL2, or V5-tagged FBL2 deletion mutant and APP ( $A$ ) or C100 (B). After treatment with the proteasome inhibitor MG132, the lysates were immunoprecipitated (IP) with anti-V5 antibody and subjected to immunoblot analysis probed with each antibody. Asterisk indicates lgG band. C, Effect of dFbox mutant on interaction of FBL2 with Skp1 and Cullin1. HEK293 cells were cotransfected with V5-tagged LacZ (control), V5-tagged FBL2, or V5-tagged FBL2 deletion mutant and APP. The lysates were immunoprecipitated with anti-V5 antibody and subjected to immunoblot analysis by probing with each antibody.

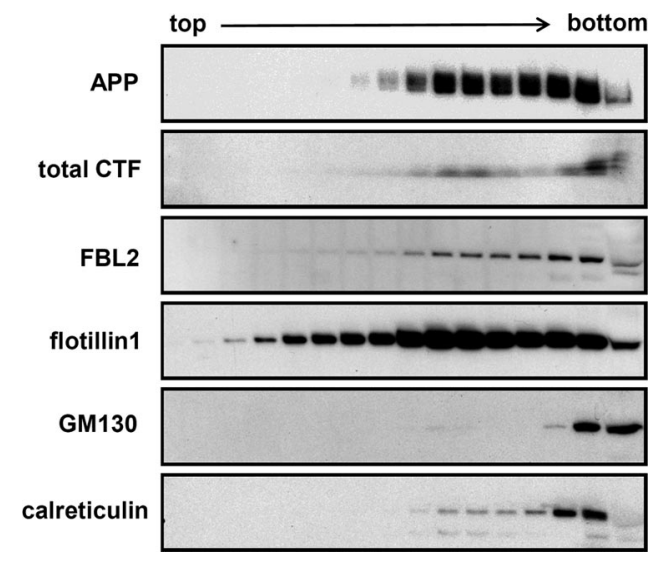

Figure 5. Subcellular localization of FBL2 and APP in mouse brains. Cerebral hemispheres from 10-week-old ICR mice were isolated and homogenized with homogenization buffer using a Dounce homogenizer. Cell lysates were resuspended in 50\% iodixanol (Axis-Shield) and subjected to step iodixanol gradient ultracentrifugation fractionation with all fractions collected in equal volumes. Collected fractions were subjected to immunoblot analysis using antibodies recognizing APP, FBL2, and the organelle-specific markers flotillin1 (lipid raft), GM130 (Golgi), and calreticulin (ER). fuged at $3000 \times g$ for $15 \mathrm{~min}$ at $4^{\circ} \mathrm{C}$. Cell lysates were resuspended in $50 \%$ iodixanol (Axis-Shield), layered on the bottom of a step gradient consisting of $20,18.5,16.5,14.5,12.5,10.5,8.5,6.5$, and $5 \%$ iodixanol solution, and centrifuged at $27,000 \mathrm{rpm}$ in a SW41Ti rotor for $20 \mathrm{~h}$ at $4^{\circ} \mathrm{C}$. Fractions were collected from the top to the bottom of the gradient and subjected to immunoblot analysis.

Cell-surface biotinylation and biotin internalization assays APP and LacZ (control) or FBL2-transfected HEK293 cells were grown in six-well plates and washed twice with ice-cold PBS. The cells were incubated in $1.5 \mathrm{ml}$ of sulfo-NHS-LC-biotin $(2 \mathrm{mg} / \mathrm{ml})$ in PBS for $1 \mathrm{~h}$ at $4^{\circ} \mathrm{C}$ with shaking and washed three times with ice-cold PBS. The cells were lysed in RIPA buffer $(0.5 \%$ sodium deoxycholate, $0.1 \%$ SDS, $1 \%$ NP- 40 , $5 \mathrm{~mm}$ EDTA, 50 mм Tris- $\mathrm{HCl}, 150 \mathrm{~mm} \mathrm{NaCl}$, and $1 \mathrm{~mm} \beta \mathrm{ME}$ ) containing protease inhibitor cocktail. Each lysate was incubated with streptavidinagarose beads for $18 \mathrm{~h}$ at $4^{\circ} \mathrm{C}$. A biotin internalization assay was performed using previously described methods (Graeve et al., 1989). Briefly, HEK293 cells transfected with APP and LacZ (control), FBL2, or FBL2 mutant were grown in six-well plates and incubated twice for $20 \mathrm{~min}$ at $4^{\circ} \mathrm{C}$ with $2 \mathrm{mg} / \mathrm{ml}$ non-membrane-permeating, cleavable biotin derivative sulfosuccinimidyl 2-(biotinamido) ethyl-1,3'-dithiopropionate (Pierce). The cells were then washed with cold PBS containing $0.1 \mathrm{M}$ glycine, washed several times with cold PBS, and incubated with culture medium for $10 \mathrm{~min}$ at $37^{\circ} \mathrm{C}$ to allow internalization of the labeled proteins. Internalization was stopped by rapid cooling on ice. To cleave biotin exposed at the cell surface, cells were incubated three times for 20 
A

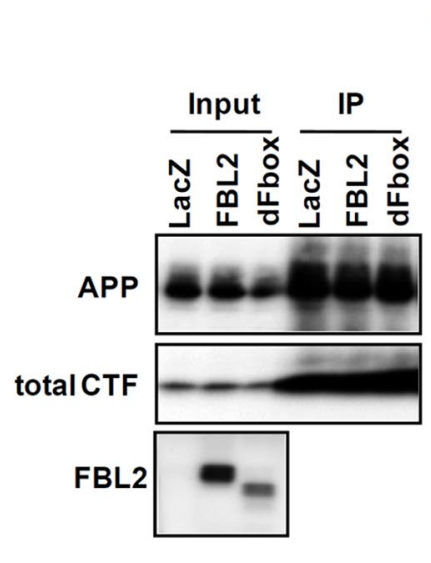

Ubiquitinated APP

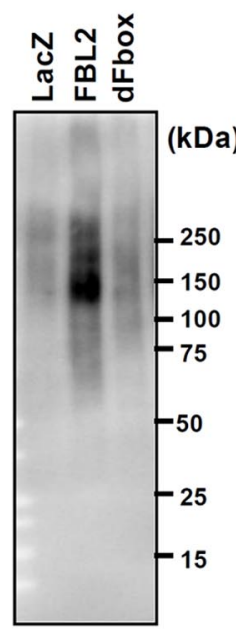

D
B

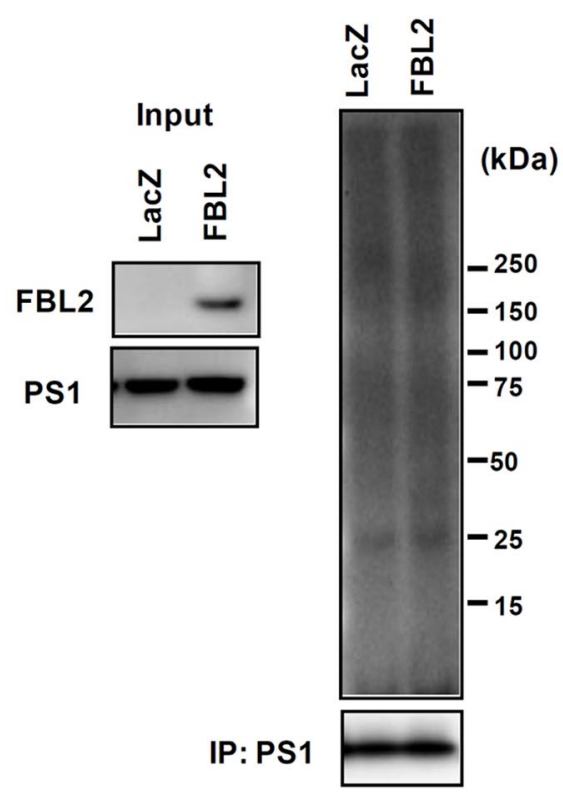

C

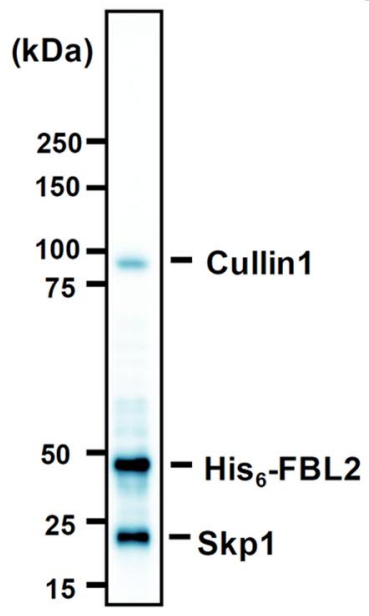

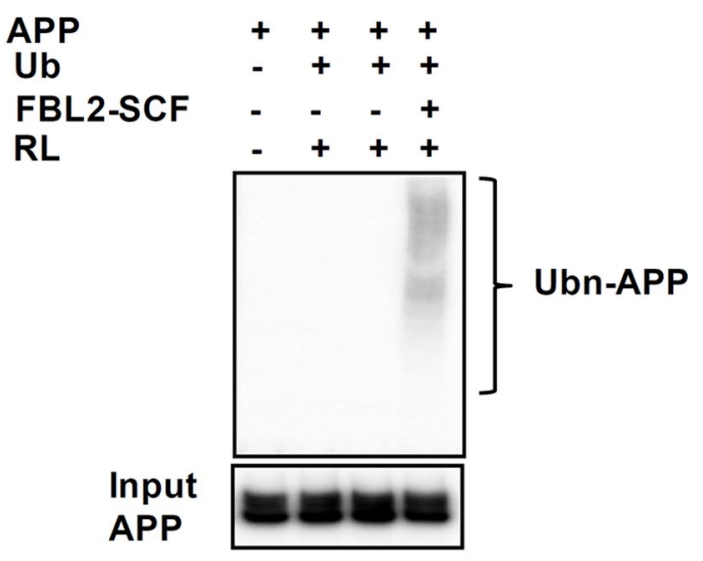

Figure 6. Promotion of APP ubiquitination by FBL2.A, HEK293 cells were cotransfected with APP and FBL2, FBL2 deletion mutant, or LacZ (control). After treatment with the proteasome inhibitor MG132, the lysates were immunoprecipitated (IP) with anti-APP antibody. Immunoblot analyses were performed with anti-APP (left) or anti-ubiquitin antibodies (P4D1) (right). B, HEK293 cells were transfected with FBL2 or LaCZ (control). After treatment with the proteasome inhibitor MG132, the lysates were immunoprecipitated with anti-PS1 antibody. Immunoblot analyses were performed with anti-ubiquitin antibodies (P4D1). C, Purified recombinant human His ${ }_{6}-\mathrm{FBL} 2$, human Skp1, and human Cullin1 expressed in E. coli were subjected to SDS-PAGE and Coomassie blue staining. D, In vitro ubiquitination assay. Purified human FBL2-Skp1-Cullin1 recombinant proteins (FBL2-SCF) were incubated with immunoprecipitated APP, ubiquitin (Ub), and rabbit reticulocyte lysates (RL) for $2 \mathrm{~h}$ at $37^{\circ}$. Immunoprecipitated APP was subjected to immunoblot analysis using anti-ubiquitin antibody.

min at $4^{\circ} \mathrm{C}$ with $50 \mathrm{~mm} 2$-mercaptoethanesulfonic acid in $50 \mathrm{~mm}$ Tris$\mathrm{HCl}, \mathrm{pH}$ 8.7, $100 \mathrm{~mm} \mathrm{NaCl}$, and $2.5 \mathrm{~mm} \mathrm{CaCl}_{2}$. After thorough rinsing with PBS containing $20 \mathrm{~mm}$ HEPES, the cells were lysed in RIPA buffer, and the internalized biotinylated proteins were immunoprecipitated with streptavidin-agarose beads and subjected to immunoblotting for APP.

\section{Lipid raft fractionation}

Transfected cells were lysed in TNE buffer (50 mM Tris-HCl, pH 7.5, 50 $\mathrm{mm} \mathrm{NaCl}, 5 \mathrm{~mm}$ EDTA, 1 mm sodium vanadate, and $0.5 \%$ Triton X-100) with Complete protease inhibitor cocktail (Roche). The Triton X-100 cell extracts were mixed with TNE buffer containing sucrose to yield a final concentration of $45 \%$ sucrose and laid at the bottom of an ultracentrifuge tube. TNE buffer containing 35 and 5\% sucrose was successively and carefully laid over the Triton X-100 cell extracts. The samples were spun at $4 \mathrm{C}^{\circ}$ for $16 \mathrm{~h}$ at $44,000 \mathrm{rpm}$ in a SW55 rotor. Fractions were then collected in $1 \mathrm{ml}$ volumes from top to bottom to yield a total of 10 fractions. Equal volumes of each fraction were subjected to SDS-PAGE and immunoblotting.

\section{Animals}

Double-transgenic AD1 mice, harboring Thy1.2 promoter-driven human $\mathrm{APP}_{\mathrm{SW}}$ and human $\mathrm{PS}_{\mathrm{M} 146 \mathrm{~V}}$ stably coinherited transgenes in a C57BL/6 background, were generated by Artemis Pharmaceuticals (referred to as ARTE10; Willuweit et al., 2009). To investigate FBL2 function in $\mathrm{APP} / \mathrm{A} \beta$ metabolism in vivo, hFBL2 transgenic mice harboring Thy1.2-human FBL2 (hFBL2) in Rosa locus were crossed with AD1 mice. Briefly, the Rosa26-FBL2 transgene targeting vector was generated by standard cloning procedures with the following order in the $5^{\prime}$ to $3^{\prime}$ direction (Seibler et al., 2003): 5' homology arm, splice acceptor, ATG start codon, neomycin resistance gene, poly(A) signal, $5^{\prime}$ Thyl promoter region, human FBL2 open reading frame and 3' Thy1 promoter region, and $3^{\prime}$ homology arm. The homology arm between exons 1 and 2 of the Rosa 26 gene was used. C57BL/6N embryonic stem cells were transfected 
with the linearized targeting vector by electroporation. After embryonic stem cell transfection, G418-resistant clones were analyzed by Southern blotting using two probes from outside of the targeting vector homology arms and one located within the construct. A homologously recombined clone harboring one targeted allele was used to generate chimeric mice by blastocyst injection. Chimeric mice were bred to C57BL/6 females, and the resulting heterozygous FBL2 transgenic mice were backcrossed with B6 mice. FBL2 transgenic mice were crossed to AD1 mice. Littermates were used as controls. All mice were housed in plastic cages, received food and water ad libitum, and were maintained on a $12 \mathrm{~h}$ inverted light/dark cycle.

\section{Measurement of soluble/insoluble $A \beta$ in brains}

Hippocampi were isolated from 7-month-old female animals, immediately frozen on dry ice, and stored at $-80^{\circ} \mathrm{C}$ until use. The samples were homogenized in ice-cold Tris-extraction buffer $(50 \mathrm{~mm}$ Tris- $\mathrm{HCl}, \mathrm{pH}$ $7.2,200 \mathrm{~mm} \mathrm{NaCl}, 2 \%$ protease-free bovine serum albumin, and $0.01 \%$ sodium merthiolate) containing protease inhibitor cocktails (Roche). After centrifugation at $15,000 \mathrm{rpm}$ for $15 \mathrm{~min}$, the supernatants were subjected to sandwich ELISA to measure the amount of soluble $A \beta$. For measurement of insoluble $\mathrm{A} \beta$, the pellets were homogenized in guanidine extraction buffer ( $5 \mathrm{~m}$ guanidine and $1 \mathrm{~m}$ Tris- $\mathrm{HCl}, \mathrm{pH} 7.2)$ and centrifuged at $15,000 \mathrm{rpm}$ for $15 \mathrm{~min}$. The supernatants were diluted with 19-fold volumes Tris-extraction buffer and subjected to ELISA.

\section{Immunohistochemistry}

Cerebral hemispheres isolated from 7-month-old female animals fixed in $4 \%$ paraformaldehyde PBS (Wako) were embedded into OTC compound (Sakura Finetek) with $15 \mu \mathrm{m}$ coronal sections cut and mounted onto silane-coated slides. Slides were pretreated with $70 \%$ formic acid for 10 min, washed with PBS, and treated with $0.3 \%$ hydrogen peroxide in methanol for $30 \mathrm{~min}$. After blocking with an M.O.M. kit (Vector Laboratories) containing $0.2 \%$ Triton $\mathrm{X}-100$ for $60 \mathrm{~min}$, slides were probed with biotinylated $\mathrm{A} \beta 6 \mathrm{E} 10$ monoclonal antibody ( $10 \mu \mathrm{g} / \mathrm{ml}$; Covance), followed with Vectastain Elite ABC Kit (mouse IgG) (Vector Laboratories), detected by DAB (Vector Laboratories). The images were captured using a NanoZoomer (Hamamatsu). The amyloid burden was quantitated using Photoshop CS (Adobe Systems).

\section{Statistical analysis}

Statistical analysis was performed by Student's $t$ test, Welch test, or Dunnett's test. A value of $p<0.05$ was considered significant.

\section{Results}

\section{FBL2 is a component of the SCF ubiquitin ligase complex}

FBL2 is a previously identified protein belonging to the family of F-box proteins that was originally cloned based on its homology to the Skp2, which is one of the best characterized proteins of this family (Ilyin et al., 1999). The FBL2 amino acid sequence is highly conserved between human and rodents (Fig. 1A). As with other SCF family members, FBL2 contains an F-box domain and also has 11 leucine-rich repeat regions for interaction with specific substrates (Fig. $1 B$ ). To examine whether FBL2 is a component of the SCF ubiquitin ligase complex, FBL2 interactions with the SCF ubiquitin ligase complex proteins Skp1 and Cullin1 were examined by immunoprecipitation assay. Skp1 or Cullin 1 protein was observed in immunoprecipitates using lysates from cells transfected with wild-type FBL2 but not in immunoprecipitates from cell lysates transfected with an FBL2 mutant lacking the F-box domain (dFbox), which is necessary to bind with Skp1 (Fig. 1C). These results clearly indicate that FBL2 binds to Skp1 and Cullin 1 in the SCF complex.

Microarray results showed that FBL2 expression levels were decreased in the brains of AD patients (Blalock et al., 2004). To confirm this previously observed decrease, we examined FBL2 mRNA levels in the brains of AD patients by quantitative PCR analysis. We found that FBL2 expression in the cortices of AD
A
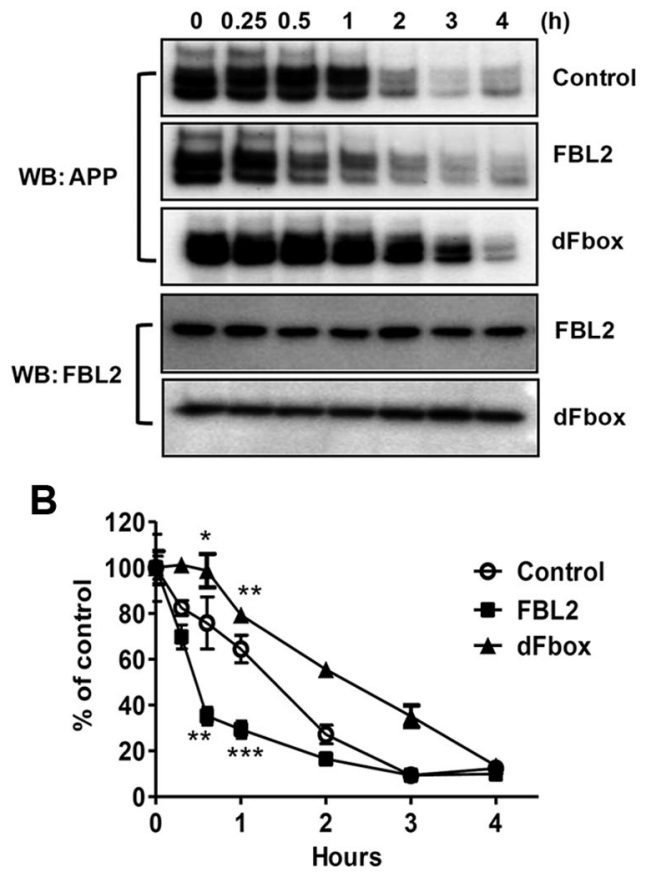

Figure 7. Promotion of APP degradation by FBL2. A, HEK293 cells cotransfected with APP and FBL2 and treated with cycloheximide $(50 \mu \mathrm{g} / \mathrm{ml})$ were harvested at the indicated times. Cell lysates were subjected to immunoblot analyses using anti-APP antibody. WB, Western blot. $\boldsymbol{B}$, The band intensities corresponding to APP in $\boldsymbol{A}$ were quantified by densitometry using a luminescent image analyzer LAS-1000 (Fujifilm). APP levels remaining at each time point were calculated as a percentage of the intensity at time 0 . Each value represents the mean \pm SEM. ${ }^{*} p<0.05,{ }^{* *} p<0.01,{ }^{* * *} p<0.01$, Dunnett's test versus control.

patients was lower than that of age-matched control subjects (Fig. 1D).

\section{Effect of FBL2 overexpression and knockdown on A $\boldsymbol{\beta}$ secretion}

We first investigated the effect of human FBL2 on $A \beta$ secretion in APP cotransfected HEK293 cells. The amount of secreted A $\beta$ decreased in FBL2-transfected cells compared with that in LacZtransfected cells. In addition, there was no change in the amount of secreted $\mathrm{A} \beta$ in cells cotransfected with the FBL2 F-box deletion mutant (dFbox), which does not appear in the SCF ubiquitin ligase complex (Fig. $2 A$ ). sAPP $\beta$ secretion also significantly decreased and $\operatorname{sAPP} \alpha$ secretion slightly decreased in FBL2transfected cells (Fig. 2 B). Furthermore, C-terminal fragment of APP generated by $\beta$-secretase $(\mathrm{CTF} \beta)$ protein produced from APP by $\beta$-secretase cleavage decreased in FBL2-transfected cells. In contrast, total CTF protein and CTF $\beta$ protein increased when the F-box deletion mutant was transfected (Fig. 2C). The expression levels of BACE1, presenilin1 (PS1), the catalytic component of $\gamma$-secretase, as well as the A $\beta$-degrading enzymes NEP and IDE were not changed during FBL2 overexpression.

Because the ubiquitin-proteasome system is known to function in the cytoplasm, we investigated the effect of mouse FBL2 overexpression on the amount of intracellular $A \beta$ in mouse Neuro2a cells stably overexpressing human APP carrying the Swedish-type familial Alzheimer mutation (swAPP-Neuro2a). The amount of intracellular $A \beta_{40}$ decreased in a gene-dosage (MOI)-dependent manner (Fig. 2D). The amount of intracellular $\mathrm{A} \beta_{42}$ was not detectable under these experimental conditions because the levels were under the detection limit. 

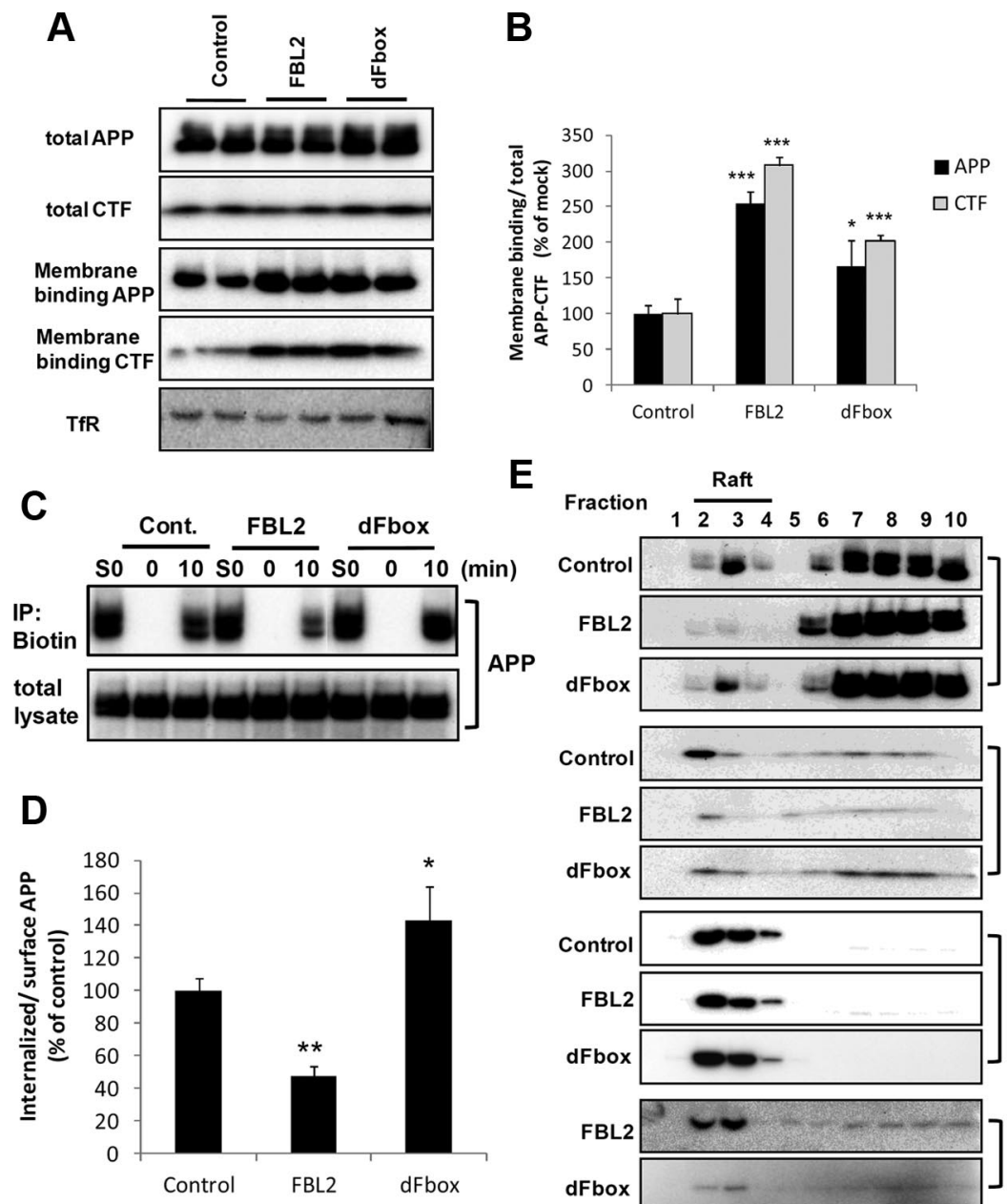

E

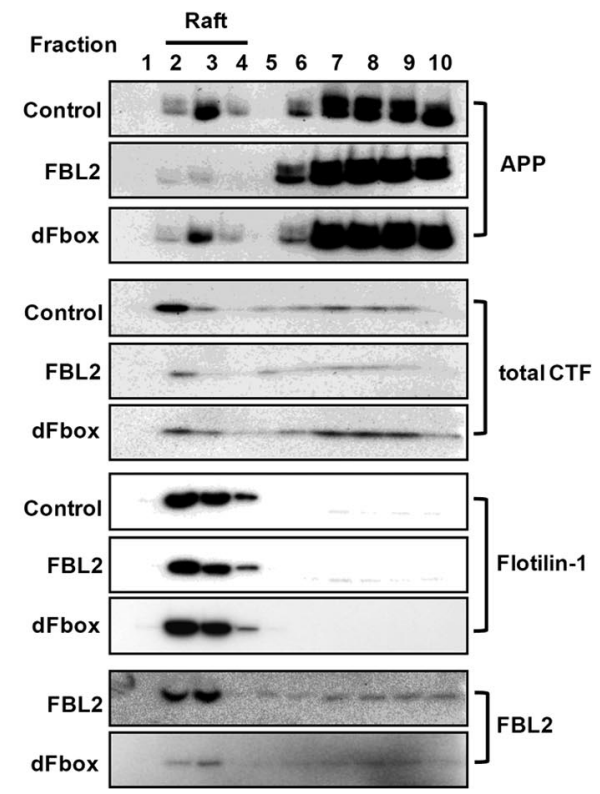

Figure 8. Decrease in the association of APP with lipid rafts in FBL2-transfected cells. A, Effect of FBL2 on cell-surface APP. HEK293 cells were cotransfected with APP and FBL2, FBL2 deletion mutant, or empty vector (control). Forty-eight hours after transfection, the surface protein of transfected cells was biotinylated at $4^{\circ} \mathrm{C}$, streptavidin agarose beads were added to the lysates, and APP levels were detected by immunoblot analysis with anti-APP antibody. B, The intensity of bands corresponding to APP and CTF in $\boldsymbol{A}$ was quantified by densitometry using a luminescent image analyzer LAS-1000 (Fujifilm). The ratios of surface-level APP or CTF relative to total APP or CTF were expressed as a percentage of the ratios in mock cells. C, Representative biotin surface labeling and internalization experiment from HEK293 cells cotransfected with APP and FBL2 or FBL2 mutant. S0 indicates the total surface labeling before removal of surface biotin, whereas 0 and 10 min indicate time points of internalization. In the bottom, equal lysate volumes were subjected to immunoblotting for APP. IP, Immunoprecipitation; Cont, Control. D, Quantitative measurement of internalized APP after 10 min and normalized with respect to surface APP at time 0 in the same experiment. $\boldsymbol{E}$, Effect of FBL2 on APP association with lipid rafts. HEK293 cells cotransfected with APP and FBL2 were lysed in Triton X-100 buffer and subjected to discontinuous sucrose density gradient ultracentrifugation fractionation. Equal volumes from each fraction were subjected to immunoblotting for APP, CTF, flotillin1, and FBL2. Means \pm SEM percentages of the relative ratio of membrane-bound APP and internalized APP levels in LacZ-transfected cells (control) are indicated. ${ }^{*} p<0.05,{ }^{* *} p<0.01,{ }^{* * *} p<0.001$, Dunnett's test.

To further confirm the inhibitory activity of FBL2 on A $\beta$ secretion, we also investigated the effect of mouse FBL2 overexpression on $\mathrm{A} \beta$ secretion from mouse cortical neurons using a lentivirus system. Compared with a LacZ overexpression control, mouse FBL2 overexpression decreased the amount of $\mathrm{A} \beta_{40}$ and $\mathrm{A} \beta_{42}$ in the medium (Fig. $2 E$ ). There was no change in the mitochondrial respiratory activity between FBL2- and LacZtransfected neurons.

We next investigated the effect of siRNA-mediated FBL2 knockdown on A $\beta$ secretion in swAPP-Neuro2a cells. We observed a reduction of endogenous FBL2 protein in FBL2-specific siRNA-treated cells (Fig. $3 B$ ). Under these experimental conditions, both $\mathrm{A} \beta_{40}$ and $\mathrm{A} \beta_{42}$ secretion significantly increased in FBL2 siRNA-treated cells (Fig. $3 A$ ). Moreover, sAPP $\beta$ produc- tion also increased in FBL2 siRNA-treated cells but did not affect $\operatorname{sAPP} \alpha$ production. In contrast to the FBL2 overexpression results, CTF $\beta$ protein increased in FBL2 knockdown cells (Fig. $3 B)$. The expression level of BACE1, PS1, NEP, and IDE was not changed in FBL2 knockdown cells. Together, these results suggest that FBL2 regulates $A \beta$ production.

\section{FBL2 interacts with APP/CTF}

To further investigate the inhibitory activity of FBL2 on $A \beta$ production, we assessed whether FBL2 interacts with APP by immunoprecipitation assay. The bands corresponding to APP and CTF were detected in cells transfected with both wildtype and the deletion mutant of FBL2 (Fig. 4A). However, BACE1 and PS1 proteins were not observed in precipitates from FBL2-transfected cells. To confirm the interaction of FBL2 with the CTF region of APP, a similar immunoprecipitation assay using cells transfected with $\mathrm{C} 100$, which consists of the C-terminal portion of APP (597-695), instead of APP was performed. A band corresponding to $\mathrm{C} 100$ was detected in both wild-type and mutant FBL2transfected cells (Fig. 4B). In contrast, when APP was cotransfected with FBL1, another F-box family protein, neither APP nor CTF bands were detected (data not shown). Together, these results indicate that FBL2 interacts with the C-terminal region of APP.

We examined the interaction of FBL2 with other SCF complex components in an immunoprecipitation assay and found that FBL2 precipitated with Skp1 or Cullin1 (Fig. 4A,B). However, these interactions were not observed for the dFbox mutant (Fig. 1C). We also examined by immunoprecipitation whether the dFbox mutant could interfere with wild-type FBL2 interactions and found that the amount of APP interacting with FBL2 in the precipitate was not changed during dFbox addition. In contrast, the amount of Skp1 or Cullin1 proteins interacting with FBL2 in the precipitate did decrease during addition of dFbox (Fig. 4C). These results suggest that this mutant acts as a dominant-negative inhibitor for assembly of the SCF complex that includes wild-type FBL2.

Based on the results showing an interaction between FBL2 and APP, we investigated the subcellular distribution of FBL2 and APP in mouse brain by immunoblot analysis of intracellular organelles from ICR mouse brain extracts separated on a $5-20 \%$ discontinuous iodixional gradient. Although some APP was observed in Golgi and ER fractions as identified by GM130 and calreticulin markers, respectively, a larger amount of APP was found in the lipid raft fraction, as detected with flotillin1. The distribution of FBL2 in the brain fractions was similar to that of APP and CTF (Fig. 5). 
FBL2 induces APP ubiquitination

We next investigated whether FBL2 ubiquitinates APP. HEK293 cells were cotransfected with APP and either wild-type FBL2, the F-box deletion mutant of FBL2, or LacZ and treated with MG132 to inhibit proteasome activity. Although the APP protein levels in the precipitates were similar for all transfected cells (Fig. 6A, left), several bands representing ubiquitinated APP in the higher-molecularweight region increased only for cells cotransfected with wild-type FBL2 (Fig. $6 A$, right). Although the F-box deletion mutant was shown to interact with APP (Fig. 4), an increase in ubiquitinated APP was not observed in cells transfected with the FBL2 deletion mutant (Fig. $6 A$, right). The ubiquitination of PS1, a key enzyme for $\mathrm{A} \beta$ production, has also been reported (Li et al., 2002). However, FBL2 overexpression did not affect PS1 ubiquitination (Fig. 6B).

To confirm the promotion of APP ubiquitination by FBL2, we generated the corresponding recombinant hexahistidine $\left(\mathrm{His}_{6}\right.$ )-tagged human FBL2 along with the components of the SCF-E3 ubiquitin ligase complex, human Skp1, and Cullin1 in E. coli, which were then purified on $\mathrm{Ni}^{2+}$ based resin (Fig. 6C). APP for substrate was isolated by immunoprecipitation from APP-transfected HEK293 cell lysates using an anti-APP antibody, because purification of soluble recombinant full-length APP was technically difficult. We incubated the purified Skp1-Cullin1-FBL2 complex with immunoprecipitated APP using the Fraction II Reticulocyte Conjugated Kit for $2 \mathrm{~h}$. APP ubiquitination did not increase after incubation with ubiquitin and rabbit reticulocyte lysates. However, APP ubiquitination did increase during addition of the purified Skp1-Cullin1-FBL2 complex (Fig. 6D). These results strongly suggest that FBL2 has E3 ubiquitin ligase activity and promotes APP ubiquitination.

\section{FBL2 promotes APP degradation}

Given that FBL2 increased APP ubiquitination, FBL2 may also promote APP degradation. In APP and FBL2 cotransfected cells, an obvious decrease in APP and CTF protein levels was not observed. However, an increase in APP and CTF protein levels was detected in cells transfected with the FBL2 deletion mutant (Fig. $2 C$ ), which raises the possibility that APP degradation was suppressed by a dominant-negative effect of the FBL2 deletion mutant. To further analyze the effect of FBL2 on APP degradation in detail, we investigated the time course of APP degradation in the presence of the protein biosynthesis inhibitor cycloheximide. APP was degraded in a time-dependent manner in mock-transfected cells, whereas the degradation was accelerated in FBL2-transfected ${ }^{* * *} p<0.001$.
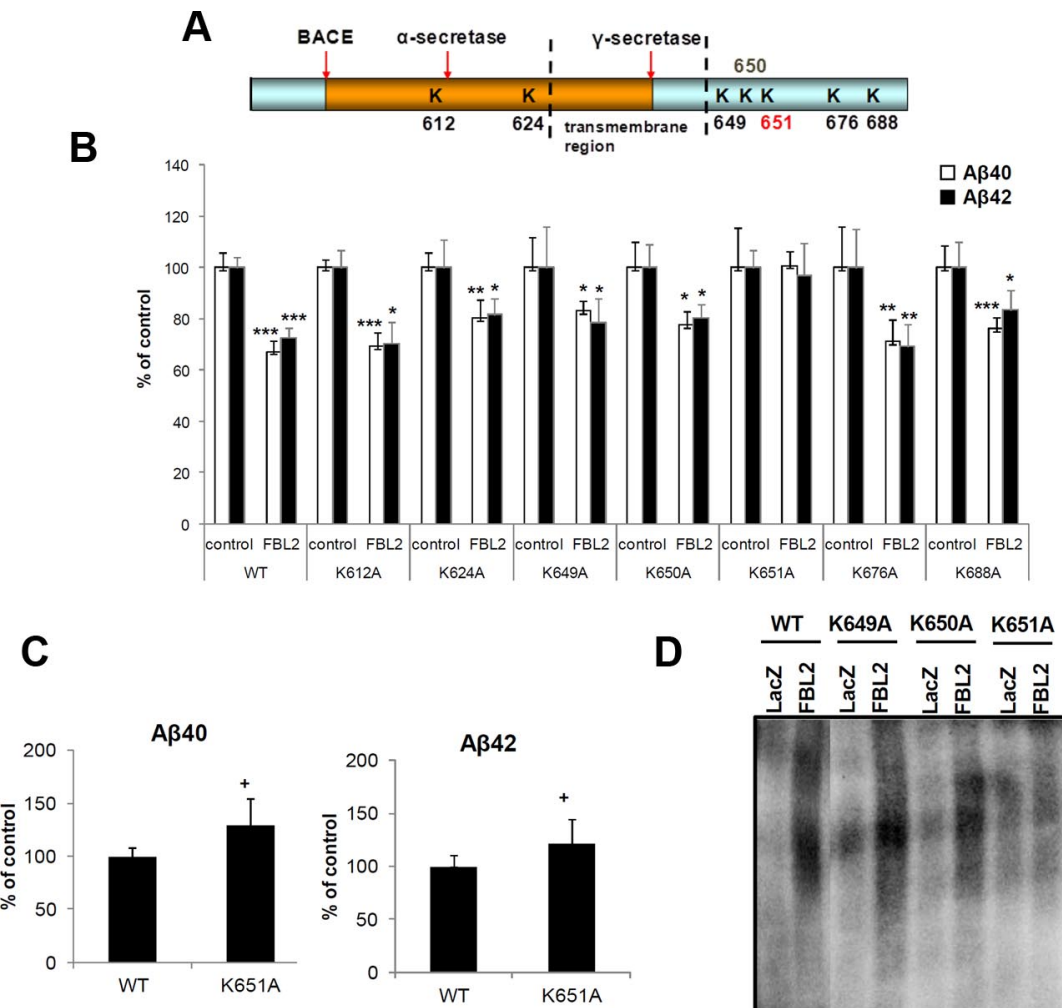

(kDa)
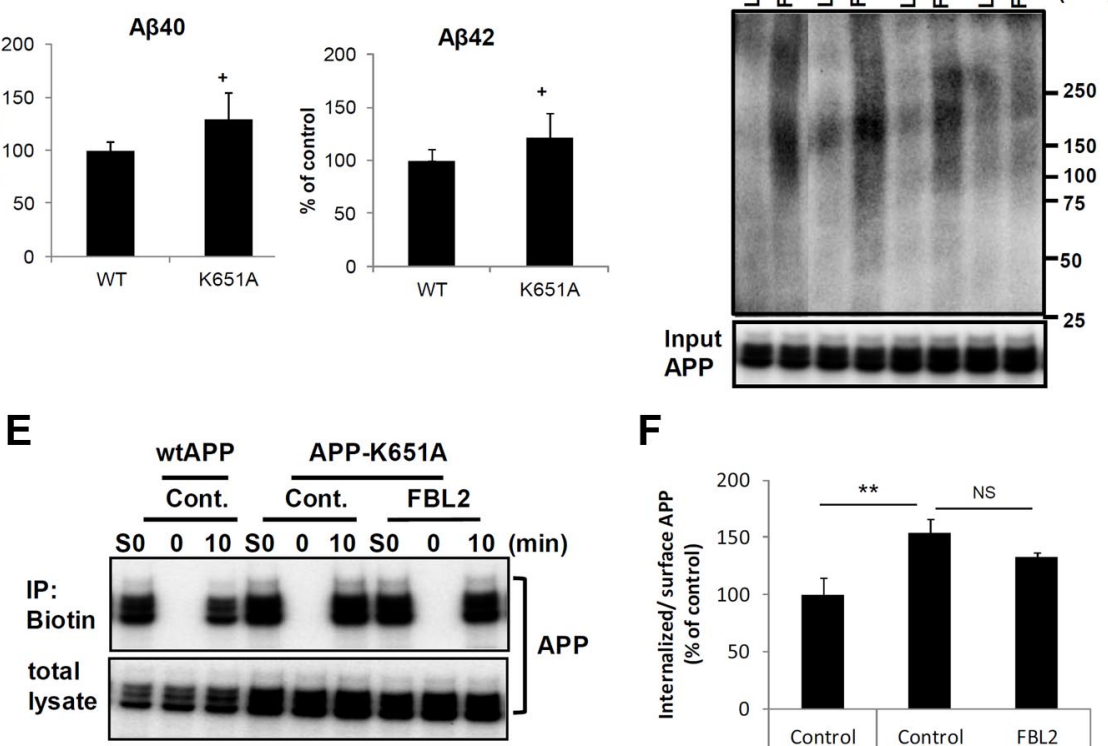

$\mathbf{F}$

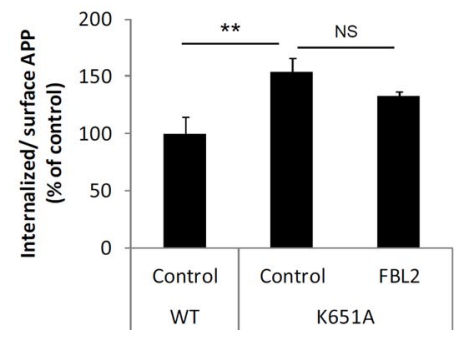

Figure 9. Effect of FBL2 on A $\beta$ production from APP mutants. $\boldsymbol{A}$, Diagram of APP lysine residues. $\boldsymbol{B}$, HEK293 cells were cotransfected with each APP mutant and FBL2 expression vectors. The medium was changed two times $18 \mathrm{~h}$ after transfection, and the amount of $A \beta$ secreted in the medium was measured by sandwich ELISA $18 \mathrm{~h}$ after the medium change. FBL2-dependent reductions in A $\beta$ levels were calculated as a percentage of each APP mutant transfected with LacZ as control. Means \pm SD percentages of the relative ratio of secreted $A \beta$ in LacZ-transfected cells (control) of each APP mutant are indicated. $C$, The amount of $A \beta$ secretion for the APP-K651A mutant was calculated as a percentage of that seen for wild-type (WT) APP. D, HEK293 cells were cotransfected with wild-type APP or APP mutant and FBL2 or LacZ (control). After treatment with the proteasome inhibitor MG132, the lysates were immunoprecipitated with anti-APP antibody. Immunoblot analyses were performed with anti-ubiquitin antibodies (P4D1). E, Representative biotin surface labeling and internalization experiment from HEK293 cells cotransfected with wild-type APP or APP mutant and FBL2 or LacZ (control). S0 indicates the total surface labeling before removal of surface biotin, whereas 0 and 10 min indicate time points of internalization. In the bottom, equal lysate volumes were subjected to immunoblotting for APP. F, Quantitative measurement of internalized APP after 10 min and normalized with respect to surface APP at time 0 in the same experiment. Data are expressed as the mean \pm SD and analyzed by Student's $t$ test; ${ }^{*} p<0.05,{ }^{* *} p<0.01$,

cells (Fig. 7). In contrast, the FBL2 deletion mutant suppressed APP degradation.

\section{FBL2 increases the amount of cell-surface APP}

Ubiquitinated proteins are typically degraded by the proteasome. However, ubiquitination is also reported to be involved in endocytosis, multivesicular body formation, and chromatin remodeling (Pickart, 2001; Hislop and von Zastrow, 2011). Furthermore, cell culture experiments showed that full-length APP is retrieved 
A
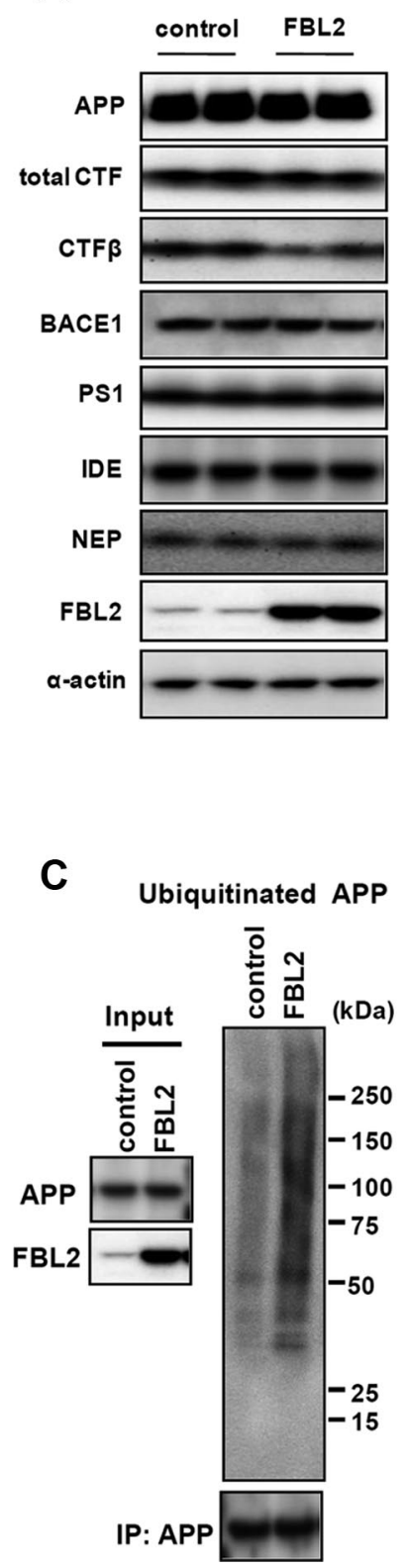

B
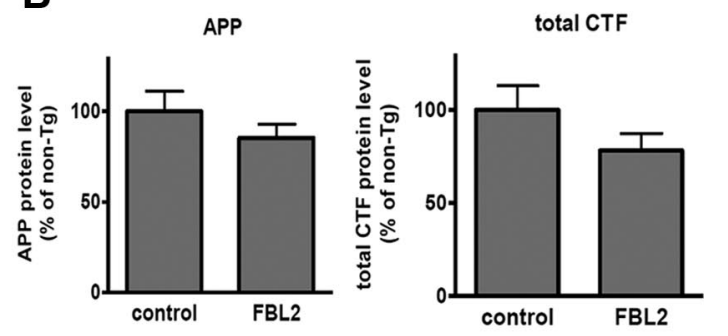

$\operatorname{CTF} \beta$

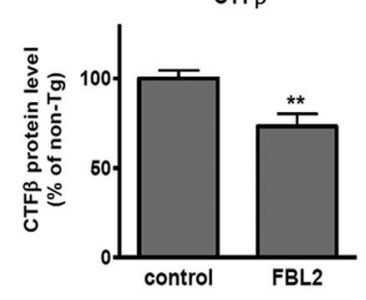

PS1
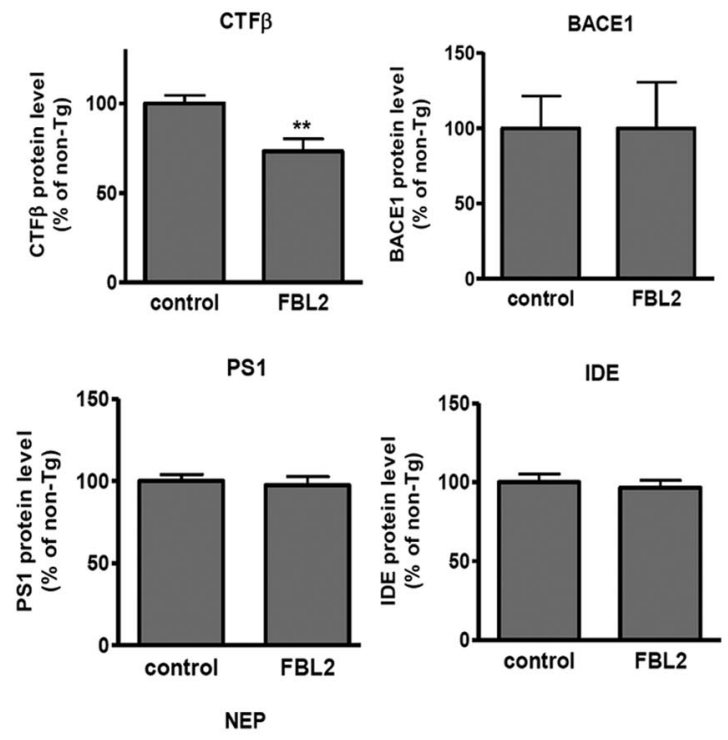

DE

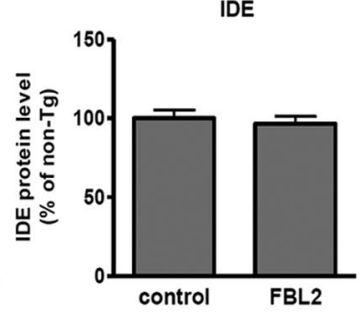

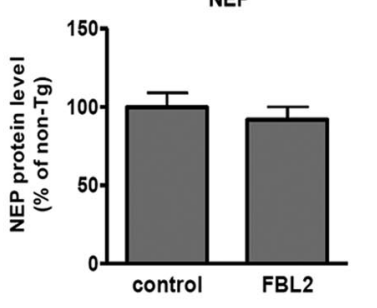

Figure 10. Effect of FBL2 on APP metabolism in AD1/FBL2 transgenic mice. $A$, Immunoblot analysis of APP, CTF, and CTF $\beta$ in hippocampus homogenates from 7-month-old AD1 mice (control mice) and FBL2 transgenic mice (AD1/FBL2 transgenic mice). $\boldsymbol{B}$, The intensities of bands corresponding to APP, CTF, and CTF $\beta$ were quantified by densitometry using a luminescent image analyzer LAS-1000 (Fujifilm). Each band was normalized with respect to the intensities of bands corresponding to $\alpha$-actin and expressed as a percentage of levels in control mice. Means \pm SE percentages of the relative ratio of each protein level in control transgenic mice are indicated. Student's $t$ test, ${ }^{* *} p<0.01$. C, APP ubiquitination in hippocampus homogenates from 7-month-old AD1 (control mice) and FBL2 transgenic mice (AD1/FBL2 transgenic mice). IP, Immunoprecipitation.

from the cell surface via clathrin-mediated endocytosis (Nordstedt et al., 1993). In both in vitro and in vivo studies, inhibition of endocytosis reduced APP internalization and $\mathrm{A} \beta$ production (Koo and Squazzo, 1994; Carey et al., 2005; Cirrito et al., 2008). We investigated the effect of FBL2-mediated ubiquitination on APP cell-surface localization. Although there was no change in the amount of total APP and CTF in FBL2-transfected cells, a substantial increase in cell-surface APP and CTF was observed (Fig. $8 A$ ). The ratio of cell surface APP to total APP also increased with FBL2 overexpression (Fig. $8 B$ ). APP and CTF on the cell surface also increased with FBL2 deletion mutant overexpression; however, the total APP and CTF was also increased with this

mutant. Compared with wild-type FBL2, the ratio of cell surface APP to total APP was reduced with the FBL2 mutant (Fig. $8 B)$. To examine whether the FBL2dependent increase in cell-surface APP resulted from inhibition of APP endocytosis, we measured APP internalization in HEK293 cells cotransfected with APP and FBL2 using a biotin internalization assay. As shown in Figure $8 C$, there was little to no biotinylated APP at time 0 , indicating that the removal of surface biotin was complete. The amount of biotinylated internalized APP relative to surface APP at 10 min was significantly decreased in FBL2-transfected cells. In contrast, cells transfected with the FBL2 deletion mutant had increased amounts of APP internalization compared with control cells (Fig. 8C,D). These results indicate that FBL2 inhibits APP endocytosis through APP ubiquitination.

Our previous results showed that FBL2 affected sAPP $\beta$ production and $\operatorname{CTF} \beta$ protein produced by $\beta$-secretase cleavage of APP. Because lipid rafts play an important role in $\beta$-secretase cleavage of APP (Tun et al., 2002; Ehehalt et al., 2003), we next examined the effect of FBL2 on APP association with lipid rafts by discontinuous sucrose density gradient analysis. Most FBL2 protein was observed in lipid rafts as indicated by the lipid raft marker flotillin1 (Fig. 8C, bottom). APP protein was also detected in lipid rafts but at decreased amounts in cells transfected with FBL2 (Fig. 8C, top). However, when cells were transfected with the FBL2 mutant, the APP protein level in lipid rafts did not change. These results suggest that FBL2 decreases the amount of APP protein localized in lipid rafts by inhibiting APP endocytosis with FBL2-mediated APP ubiquitination being essential for this decrease.

\section{FBL2 does not ubiquitinate APP at lysine 651}

To identify the APP ubiquitination site for FBL2, we generated APP mutants in which each lysine was replaced with alanine and examined the effect of FBL2 on APP ubiquitination. There are seven lysine residues in the CTF $\beta$ region of APP (Fig. $9 A)$. First, we examined the effect of FBL2 on $\mathrm{A} \beta$ production from each APP mutant. Among the APP mutants, $A \beta$ reduction by FBL2 overexpression did not occur only for the APP 651 lysine mutant (K651A) (Fig. 9B). FBL2-dependent APP ubiquitination did not increase for the APP-K651A mutant; however, an increase in APP ubiquitination by FBL2 was observed for the other APP mutants (Fig. 9D). The amount of $A \beta$ secretion significantly increased for the APP-K651A mutant compared with that of wild-type APP (Fig. 9C). APP internalization was also inhibited for the APP-K651A mutant compared with wild-type APP. Fur- 
A soluble $A \beta$

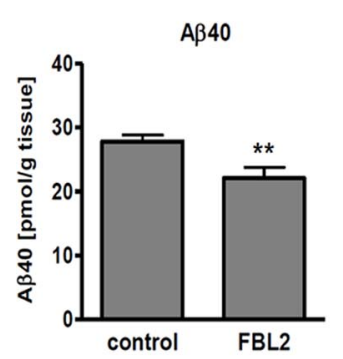

\section{Control}

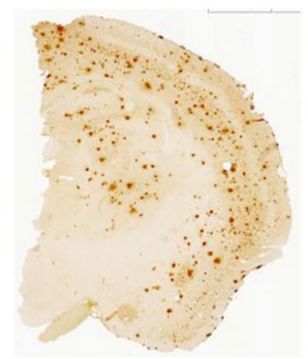

E E Control

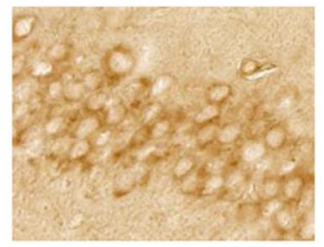

A 342

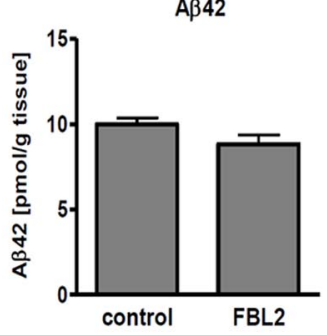

FBL2

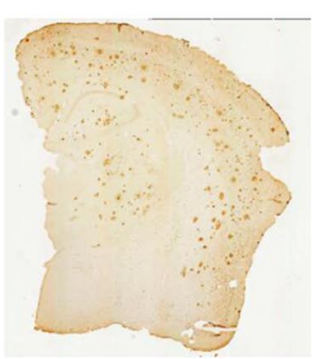

FBL2

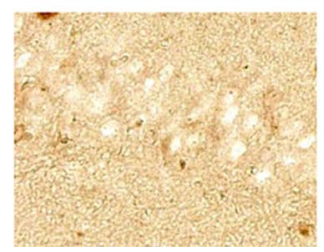

B

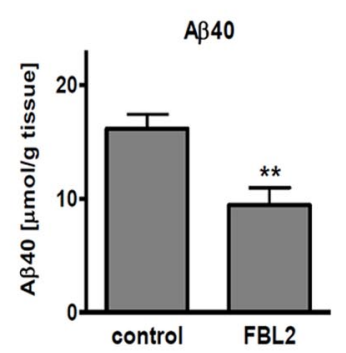

D

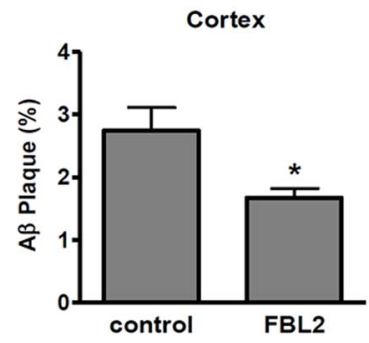

A 342
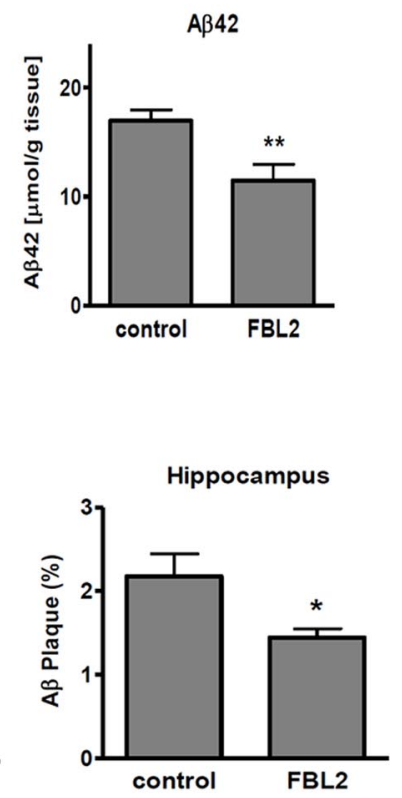

Figure 11. Reduction of insoluble $A \beta$ in AD1/FBL2 transgenic mice. Tris-soluble $A \beta(A)$ and Tris-insoluble $A \beta(B)$ in hippocampi of control and FBL2 transgenic mice were measured by ELISA. $C, A \beta$ immunohistochemistry of coronal sections from brains of control (left) or FBL2 (right) transgenic mice. $D$, Amyloid burden (percentage of area by $A \beta$ immunoreactivity) in the cortex (left) or hippocampus (right) of control or FBL2 transgenic mice. $E$, Intraneuronal $A \beta$ in CA1 of hippocampus of control or FBL2 transgenic mice. Data are expressed as the mean \pm SEM and analyzed by Student's $t$ test; ${ }^{*} p<0.05,{ }^{* *} p<0.01$.

thermore, the increase in APP internalization promoted by FBL2 was not observed for the APP-K651A mutant (Fig. 9E,F). These results suggest that the lysine residue 651 of APP plays an important role in APP metabolism and that FBL2 can regulate APP metabolism by promoting ubiquitination at this site.

\section{Levels of $\mathrm{A} \boldsymbol{\beta}$ are reduced in FBL2/AD1 mouse brains}

To confirm the effect of FBL2 on APP metabolism in vivo, we generated FBL2 transgenic mice in which FBL2 expression is driven by the neuron-specific Thyl promoter element, and these animals were crossed with double-transgenic mice (AD1) harboring APPswe and $\mathrm{PS} 1_{\mathrm{M} 146 \mathrm{~V}}$ transgenes. An increase in the FBL2 protein level was confirmed in FBL2 transgenic mice compared with control mice at 7 months of age (Fig. 10A). APP and total CTF protein levels also tended to decrease with CTF $\beta$ protein amounts being significantly decreased in FBL2 transgenic mice (Fig. 10 A, B). However, BACE1, PS1, and A $\beta$-degrading enzyme (NEP, IDE) protein levels was not changed in FBL2 transgenic mice. To confirm whether FBL2 functions in vivo, we examined APP ubiquitination levels in FBL2 transgenic mice and found that ubiquitinated APP levels were increased in FBL2 transgenic mice relative to control mice (Fig. 10C).

We first measured the levels of Tris-soluble and insoluble $\mathrm{A} \beta$ in the hippocampus of FBL2 transgenic mice. Soluble $\mathrm{A} \beta_{40}$ was significantly reduced in the hippocampus of FBL2 transgenic mice (Fig. 11A). Interestingly, the amount of insoluble $\mathrm{A} \beta_{40}$ and $\mathrm{A} \beta_{42}$ was also reduced in FBL2 transgenic mice (Fig. $11 B$ ). We next analyzed the effect of FBL2 on the formation of $A \beta$ plaques using immunohistochemistry. The $\mathrm{A} \beta$ plaque burden (percentage area covered by $\mathrm{A} \beta$ immunoreactivity) in the cortex and hippocampus of FBL2 transgenic mice was remarkably reduced compared with that of nontransgenic mice (Fig. 11C). Quantitative analysis demonstrated that the $\mathrm{A} \beta$ plaque burden was reduced by $\sim 40 \%$ in FBL2 transgenic mice (Fig. $11 D$ ), which is in agreement with the biochemical data. Intraneuronal $A \beta$ accumulation was observed in CA1 region pyramidal neurons of $\mathrm{AD} 1$ mice (Fig. $11 E$, left). Interestingly, the intraneuronal $A \beta$ accumulation also decreased in FBL2 transgenic mice (Fig. 11E, right).

\section{Discussion}

FBL2 expression was reported to decrease in the brains of $A D$ patients (Eric et al., 2004). FBL2 is likely to be involved in ubiquitination regulation via its F-box domain and leucine rich repeat region that are needed to participate in SCF-E3 ubiquitin ligase complex formation and binding of specific substrates, respectively. However, FBL2 function and the identity of its substrates remained unclear. In this study, we showed that FBL2 mRNA 


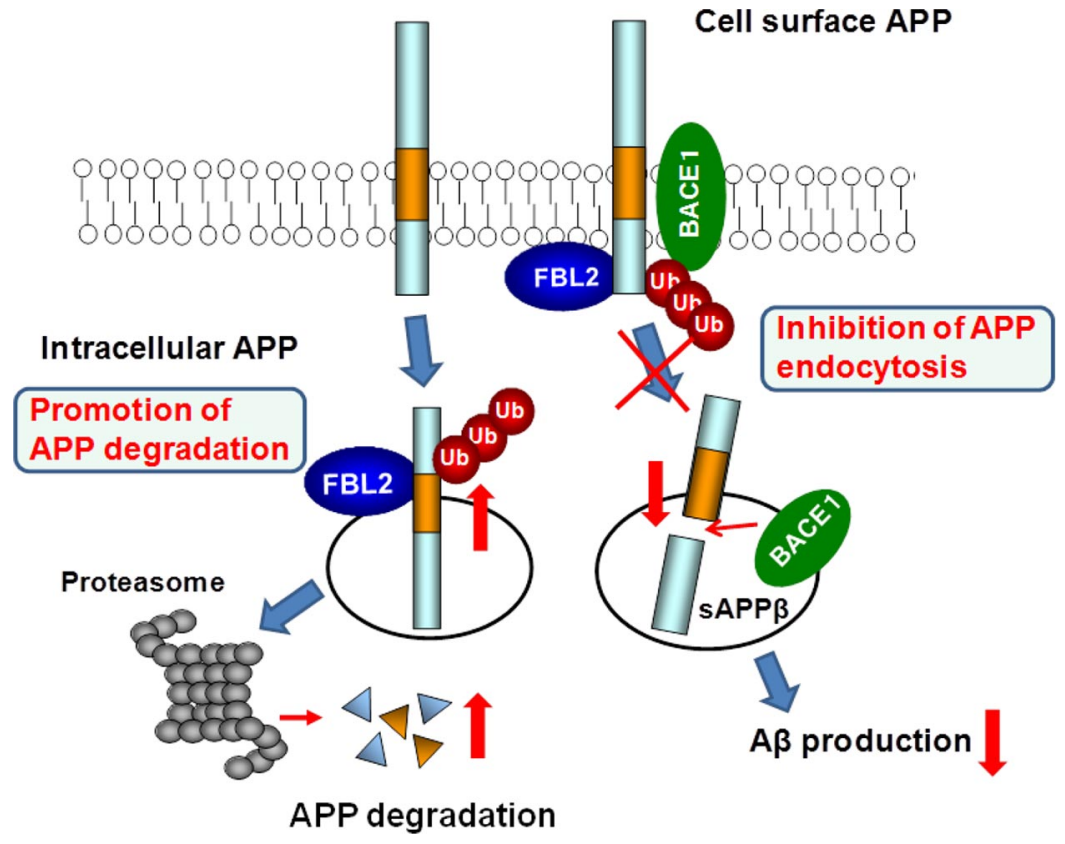

Figure 12. Schematic representation of APP metabolism regulation by FBL2. FBL2 has a dual function on APP metabolism by regulating its ubiquitination. FBL2 promotes ubiquitination of intracellular APP, which is then degraded by the proteasome. FBL2 also promotes ubiquitination of cell-surface APP. Ubiquitinated cell-surface APP does not undergo endocytosis and subsequently decreases the amount of APP protein in lipid rafts and $\beta$-secretase APP cleavage.

expression levels decreased in the brains of $\mathrm{AD}$ patients and that FBL2 reduced the amount of both intracellular and secreted $\mathrm{A} \beta$ in neuronal cultures by binding APP and promoting its ubiquitination. We also demonstrated that FBL2 facilitated APP degradation and localization in lipid rafts by inhibiting APP endocytosis (Fig. 12). FBL2 had no effect on the protein expression levels of the $\mathrm{A} \beta$-producing enzymes (BACE1, PS1) or $\mathrm{A} \beta$ degrading enzymes (NEP, IDE). Furthermore, a significant decrease in insoluble $\mathrm{A} \beta$ and $\mathrm{A} \beta$ plaques was observed in the brains of AD1 mice crossed with FBL2 (AD1/FBL2) transgenic mice. These findings indicate a novel pathway for APP/A $\beta$ metabolism whereby FBL2 regulates APP ubiquitination.

Recent studies suggest that intracellular $A \beta$ accumulation plays an important role in $\mathrm{AD}$ neural dysfunction. Intracellular $\mathrm{A} \beta_{42}$ accumulation occurs in the pyramidal neurons of the hippocampus and entorhinal cortex long before the emergence of $\mathrm{A} \beta$ plaques and paired helical filaments in the brains of $\mathrm{AD}$ patients (Gouras et al., 2000; D'Andrea et al., 2001; Tabira et al., 2002). In addition, an apoptosis marker was detected in a subset of $\mathrm{A} \beta_{42}$ accumulating neurons in the brains of Down's syndrome patients (Busciglio et al., 2002). Furthermore, initial cognitive impairment in triple-transgenic mice was observed at 4 months of age when intraneuronal $\mathrm{A} \beta$ accumulation was present but $\mathrm{A} \beta$ plaque and tangle pathology was not yet apparent (Oddo et al., 2003). This cognitive impairment was rescued by clearance of intraneuronal $\mathrm{A} \beta$ pathology using anti- $\mathrm{A} \beta$ antibody immunotherapy (Billings et al., 2005). These findings strongly suggest that intraneuronal $\mathrm{A} \beta$ accumulation is closely linked to cognitive impairment in $\mathrm{AD}$. We showed in this study that intraneuronal $\mathrm{A} \beta$ accumulation in pyramidal neurons of AD1/FBL2 transgenic mice hippocampi were markedly decreased. In addition, FBL2 overexpression decreased intracellular A $\beta$ in swAPP-Neuro2a cells, although a decrease in secreted $A \beta$ was not observed (data not shown). These results strongly suggest that enhancement of FBL2 function is expected to be a novel therapeutic strategy for $\mathrm{AD}$, which could facilitate reduction of intraneuronal $\mathrm{A} \beta$.
Although mutant FBL2 lacking the F-box domain was shown to bind APP, cells transfected with this mutant had no change in the amount of secreted $A \beta$. Furthermore, $A \beta$ reduction and an increase in APP ubiquitination by FBL2 were not observed for the APP-K651A mutant. The amount of secreted $A \beta$ increased and APP endocytosis was inhibited in the APP-K651A mutant compared with wildtype APP. These results clearly indicate that the FBL2 ubiquitination site at lysine 651 of APP is required for FBL2-mediated regulation of $A \beta$ production. In addition, FBL2 has been shown to associate with the plasma membrane through geranylgeranylation of its $\mathrm{C}$-terminal region (Wang et al., 2005). Furthermore, an FBL2 mutant in which cysteine 420 was replaced with a serine residue that abolished FBL2 binding to the plasma membrane did not affect $\mathrm{A} \beta$ secretion when cotransfected with APP in HEK293T cells (data not shown). Collectively, FBL2 may translocate to the plasma membrane in which it facilitates APP ubiquitination, leading to a reduction in the amount of $\mathrm{A} \beta$ secretion.

Previous studies showed that full-length and C-terminal fragments of APP generated by $\beta$-secretase (CTF $\beta$ ) were ubiquitinated and degraded in a proteasome-dependent manner (Nunan et al., 2001, 2003, Kaneko et al., 2010). We demonstrated in a time course experiment with cycloheximide that FBL2 overexpression accelerated ubiquitination-dependent APP degradation in a time-dependent manner. FBL2 overexpression was also expected to reduce the amount of APP in vivo. However, the effect of FBL2 on APP protein levels was unclear in AD1/FBL2 transgenic mice (referred to as ARTE10 by Willuweit et al., 2009), because of high APP expression levels that could preclude detection of changes in the amount of APP. However, we did confirm that APP ubiquitination was increased in AD1/FBL2 transgenic mice. In addition, the binding of FBL2 with APP decreased in the absence of proteasome inhibitor in an immunoprecipitation study (data not shown). These results collectively suggest that APP ubiquitinated by FBL2 is immediately degraded by the proteasome. It is interesting to note that the increase in the amount of both APP and CTF were observed in cells cotransfected with the FBL2 deletion mutant and APP. This result might be attributable to the dominant-negative effect of deletion mutant and APP protein complexes that inhibit proteasome function in steady-state APP degradation.

The ubiquitin system has an important role in regulating a broad array of cellular functions, including cell-cycle progression, DNA repair, membrane protein transport, and signal transduction in addition to proteasomal protein degradation (Hofmann and Pickart, 1999; Pickart, 2001; Hislop and von Zastrow, 2011). Furthermore, mono-ubiquitination has signaling functions in the endocytic pathway (Hicke, 2001; Hicke and Dunn, 2003). There are many reports on regulation of receptor through the ubiquitination. Ubiquitinated receptor was known to be generally promoted to endocytic internalization (Haglund et al., 2003; Sigismund et al., 2005; Hislop and Zastrow, 2011). In contrast, our results show that FBL2-mediated ubiquitination of APP inhibits its endocytosis, which is further supported by the 
inability of the FBL2 deletion mutant lacking ubiquitin ligase activity to inhibit endocytosis and inhibition of APP endocytosis in APP-K651A mutant. This situation is similar to previous reports that ubiquitination negatively regulated internalization of protease-activated receptor-1, a G-protein-coupled receptor for thrombin (Wolfe et al., 2007). This evidence suggests that ubiquitination can both positively and negatively regulate receptor internalization.

One major pathway of $A \beta$ generation begins by endocytosis of APP from the plasma membrane into the endocytic compartment, and then APP is cleaved by $\beta$-secretase (BACE) and $\gamma$-secretase within late and early endosome to produce $\mathrm{A} \beta$ (Vassar et al., 1999; Lah and Levey, 2000). Inhibition of endocytosis increased the amount of APP on the cell surface and reduced A $\beta$ production both in vitro and in vivo (Koo and Squazzo, 1994; Carey et al., 2005; Cirrito et al., 2008). RanBP9 was recently shown to decrease the amount of APP on the cell surface without affecting total APP amounts and consequently increased secreted $\mathrm{A} \beta$ level through increased BACE1 cleavage of APP (Lakshmana et al., 2009). Furthermore, phosphatidylinositol-binding clathrin assembly protein (PICALM) was found to be a novel genetic risk factor for AD by a genome-wide association study (Harold et al., 2009), and an association between PICALM and brain atrophy or CSF A $\beta_{42}$ level was recently reported (Biffi et al., 2010; Schjeide et al., 2011). Because PICALM is an important factor for endocytosis (Ford et al., 2001), these findings support a role for dysregulation of APP endocytosis in the pathogenic mechanism of AD. This mechanism is further supported by our result in which FBL2 affected APP metabolism by regulating APP endocytosis. Our results showed that inhibition of APP endocytosis by FBL2 led to a decrease in the amount of APP protein in lipid rafts and $\beta$-secretase APP cleavage. We also showed a reduction in $\operatorname{sAPP} \beta$ production and CTF $\beta$ protein by BACE1 cleavage in FBL2overexpressing cells.

In conclusion, we demonstrated a novel mechanism for APP metabolism through FBL2-mediated APP ubiquitination. The activation of FBL2 function by increasing protein expression and/or the enzyme activity is expected to facilitate $\mathrm{A} \beta$ reduction in the brain, especially intraneuronal $\mathrm{A} \beta$ that is directly linked to cognitive deficit.

\section{References}

Alves-Rodrigues A, Gregori L, Figueiredo-Pereira ME (1998) Ubiquitin, cellular inclusions and their role in neurodegeneration. Trends Neurosci 21:516-520.

Bedford L, Lowe J, Dick LR, Mayer RJ, Brownell JE (2011) Ubiquitin-like protein conjugation and the ubiquitin-proteasome system as drug targets. Nat Rev Drug Discov 10:29-46.

Biffi A, Anderson CD, Desikan RS, Sabuncu M, Cortellini L, Schmansky N, Salat D, Rosand J; Alzheimer's Disease Neuroimageing Initiative (ADNI) (2010) Genetic variation and neuroimaging measures in Alzheimer disease. Arch Neurol 67:677-685.

Billings LM, Oddo S, Green KN, McGaugh JL, LaFerla FM (2005) Intraneuronal Abeta causes the onset of early Alzheimer's disease-related cognitive deficits in transgenic mouse. Neuron 45:675-688.

Blalock EM, Geddes JW, Chen KC, Porter NM, Markesbery WR, Landfield PW (2004) Incipient Alzheimer's disease: microarray correlation analyses reveal major transcriptional and tumor suppressor responses. Proc Natl Acad Sci U S A 101:2173-2178.

Busciglio J, Pelsman A, Wong C, Pigino G, Yuan M, Mori H, Yankner BA (2002) Altered metabolism of the amyloid beta precursor protein is associated with mitochondrial dysfunction of Down's syndrome. Neuron 33:677-688.

Carey RM, Balcz BA, Lopez-Coviella I, Slack BE (2005) Inhibition of dynamin-dependent endocytosis increases shedding of the amyloid pre- cursor protein ectodomain and reduces generation of amyloid beta protein. BMC Cell Biol 6:30.

Chen L, Thiruchelvam MJ, Madura K, Richfield EK (2006) Proteasome dysfunction in aged human alpha-synuclein transgenic mice. Neurobiol Dis 23:120-126.

Ciechanover A, Brundin P (2003) The ubiquitin proteasome system in neurodegenerative diseases. Neuron 40:427-446.

Cirrito JR, Kang JE, Lee J, Stewart FR, Verges DK, Silverio LM, Bu G, Mennerick S, Holtzman DM (2008) Endocytosis is required for synaptic activity-dependent release of amyloid- $\beta$ in vivo. Neuron 58:42-51.

D'Andrea MR, Nagele RG, Wang HY, Peterson PA, Lee DH (2001) Evidence that neurons accumulating amyloid can undergo lysis to form amyloid plaques in Alzheimer's disease. Histopathology 38:120-134.

Ehehalt R, Keller P, Haass C, Thiele C, Simons K (2003) Amyloidogenic processing of Alzheimer $\beta$-amyloid precursor protein depends on lipid rafts. J Cell Biol 160:113-123.

Ford MG, Pearse BM, Higgins MK, Vallis Y, Owen DJ, Gibson A, Hopkins CR, Evans PR, McMahon HT (2001) Simultaneous binding of PtdIns(4,5)P2 and clathrin by AP180 in the nucleation of clathrin lattices on membranes. Science 291:1051-1055.

Gouras GK, Tsai J, Naslund J, Vincent B, Edgar M, Checler F, Greenfield JP, Haroutunian V, Buxbaum JD, Xu H, Greengard P, Relkin NR (2000) Intraneuronal Abeta42 accumulation in human brain. Am J Pathol 156:15-20.

Graeve L, Drickamer K, Rodriguez-Boulan E (1989) Polarized endocytosis by Madin-Darby canine kidney cells transfected with functional chicken liver glycoprotein receptor. J Cell Biol 109:2809-2816.

Haglund K, Sigismund S, Polo S, Szymkiewicz I, Di Fiore PP, Dikic I (2003) Multiple monoubiquitination of RTKs is sufficient for their endocytosis and degradation. Nat Cell Biol 5:461-466.

Haass C, Selkoe DJ (2007) Soluble protein oligomers in neurodegeneration: lessons from the Alzheimer's amyloid $\beta$-peptide. Nat Rev Mol Cell Biol 8:101-112.

Haass C, Lemere CA, Capell A, Citron M, Seubert P, Schenk D, Lannfelt L, Selkoe DJ (1995) The Swedish mutation causes early-onset Alzheimer's disease by $\beta$-secretase cleavage within the secretory pathway. Nat Med 1:1291-1296.

Harold D, Abraham R, Hollingworth P, Sims R, Gerrish A, Hamshere ML, Pahwa JS, Moskvina V, Dowzell K, Williams A, Jones N, Thomas C, Stretton A, Morgan AR, Lovestone S, Powell J, Proitsi P, Lupton MK, Brayne C, Rubinsztein DC, et al. (2009) Genome-wide association study identifies variants at CLU and PICALM associated with Alzheimer's disease. Nat Genet 42:1088-1093.

Hershko A, Ciechanover A, Varshavsky A (2000) Basic Medical Research Award: the ubiquitin system. Nat Med 6:73-1081.

Hicke L (2001) Protein regulation by monoubiquitination. Nat Rev Mol Cell Biol 2:195-201.

Hicke L, Dunn R (2003) Regulation of membrane protein transport by ubiquitin and ubiquitin-binding proteins. Annu Rev Cell Dev Biol 19:141-172.

Hislop JN, von Zastrow M (2011) Role of ubiquitination in endocytic trafficking of G-protein-coupled receptors. Traffic 12:137-148.

Hofmann RM, Pickart CM (1999) Noncanonical MMS2-encoded ubiquitinconjugating enzyme functions in assembly of novel polyubiquitin chains for DNA repair. Cell 96:645-653.

Ilyin GP, Rialland M, Glaise D, Guguen-Guillouzo C (1999) Identification of a novel Skp2-like mammalian protein containing F-box and leucinerich repeats. FEBS Lett 459:75-79.

Kaneko M, Koike H, Saito R, Kitamura Y, Okuma Y, Nomura Y (2010) Loss of HRD1-mediated protein degradation causes amyloid precursor protein accumulation and amyloid- $\beta$ generation. J Neurosci 30:3924-3932.

Kitada T, Asakawa S, Hattori N, Matsumine H, Yamamura Y, Minoshima S, Yokochi M, Mizuno Y, Shimizu N (1998) Mutations in the parkin gene cause autosomal recessive juvenile parkinsonism. Nature 392:605-608.

Koo EH, Squazzo SL (1994) Evidence that production and release of amyloid beta-protein involves the endocytic pathway. J Biol Chem 269:17386-17389.

Lah JJ, Levey AI (2000) Endogenous presenilin-1 targets to endocytic rather than biosynthetic compartments. Mol Cell Neurosci 16:111-126.

Lakshmana MK, Yoon IS, Chen E, Bianchi E, Koo EH, Kang DE (2009) Novel role of RanBP9 in BACE1 processing of amyloid precursor protein and amyloid peptide generation. J Biol Chem 284:11863-11872. 
Lam YA, Pickart CM, Alban A, Landon M, Jamieson C, Ramage R, Mayer RJ, Layfield R (2000) Inhibition of the ubiquitin-proteasome system in Alzheimer's disease. Proc Natl Acad Sci U S A 97:9902-9906.

Li J, Pauley AM, Myers RL, Shuang R, Brashler JR, Yan R, Buhl AE, Ruble C, Gurney ME (2002) SEL-10 interacts with presenilin1, facilitates its ubiquitination, and alters A-beta peptide production. J Neurochem 82:15401548.

López Salon L, Morelli L, Castaño EM, Soto EF, Pasquini JM (2000) Defective ubiquitination of cerebral proteins in Alzheimer's disease. J Neurosci Res 62:302-310.

Nordstedt C, Caporaso GL, Thyberg J, Gandy SE, Greengard P (1993) Identification of the Alzheimer beta/A4 amyloid precursor protein in clathrincoated vesicles purified from PC12 cells. J Biol Chem 268:608-612.

Nunan J, Shearman MS, Checler F, Cappai R, Evin G, Beyreuther K, Masters CL, Small DH (2001) The C-terminal fragment of the Alzheimer's disease amyloid protein precursor is degraded by a proteasome-dependent mechanism distinct from gamma-secretase. Eur J Biochem 268:53295336.

Nunan J, Williamson NA, Hill AF, Sernee MF, Masters CL, Small DH (2003) Proteasome-mediated degradation of the C-terminus of the Alzheimer's disease beta-amyloid protein precursor: effect of C-terminal truncation on production of beta-amyloid protein. J Neurosci Res 74:378-385.

Oddo S, Caccamo A, Shepherd JD, Murphy MP, Golde TE, Kayed R, Metherate R, Mattson MP, Akbari Y, LaFerla FM (2003) Triple-transgenic model of Alzheimer's disease with plaques and tangles: intracellular Abeta and synaptic dysfunction. Neuron 39:409-421.

Ortega Z, Díaz-Hernández M, Maynard CJ, Hernández F, Dantuma NP, Lucas JJ (2010) Acute polyglutamine expression in inducible mouse model unravels ubiquitin/proteasome system impairment and permanent recovery attributable to aggregate formation. J Neurosci 30:36753688.

Perry G, Friedman R, Shaw G, Chau V (1987) Ubiquitin is detected in neurofibrillary tangles and senile plaque neuritis of Alzheimer disease brain. Proc Natl Acad Sci U S A 84:3033-3036.

Pickart CM (2001) Ubiquitin enters new millennium. Mol Cell 8:499-504.

Schjeide BM, Schnack C, Lambert JC, Lill CM, Kirchheiner J, Tumani H, Otto M, Tanzi RE, Lehrach H, Amouyel P, von Arnim CA, Bertram L (2011) The role of clusterin, complement receptor 1, and phosphatidylinositol binding clathrin assembly protein in Alzheimer disease risk and cerebrospinal fluid biomarker levels. Arch Gen Psychiatry 68:207-213.

Seibler J, Zevnik B, Küter-Luks B, Andreas S, Kern H, Hennek T, Rode A, Heimann C, Faust N, Kauselmann G, Schoor M, Jaenisch R, Rajewsky K, Kühn R, Schwenk F (2003) Rapid generation of inducible mouse mutants. Nucleic Acids Res 31:e12.

Selkoe DJ (1998) The cell biology of beta-amyloid precursor protein and presenilin in Alzheimer's disease. Trends Cell Biol 8:447-453.
Shimura H, Hattori N, Kubo S, Mizuno Y, Asakawa S, Minoshima S, Shimizu N, Iwai K, Chiba T, Tanaka K, Suzuki T (2000) Familial Parkinson disease gene product, parkin, is a ubiquitin-protein ligase. Nat Genet 25:302-305.

Sigismund S, Woelk T, Puri C, Maspero E, Tacchetti C, Transidico P, Di Fiore PP, Polo S (2005) Clathrin-independent endocytosis of ubiquitinated cargos. Proc Natl Acad Sci U S A 102:2760-2765.

Suzuki N, Iwatsubo T, Odaka A, Ishibashi Y, Kitada C, Ihara Y (1994) High tissue content of soluble beta 1-40 is linked to cerebral amyloid angiopathy. Am J Pathol 145:452-460.

Tabira T, Chui DH, Kuroda S (2002) Significance of intracellular Abeta42 accumulation in Alzheimer's disease. Front Biosci 7:a44-a49.

Tan Z, Sun X, Hou FS, Oh HW, Hilgenberg LG, Hol EM, van Leeuwen FW, Smith MA, O'Dowd DK, Schreiber SS (2007) Mutant ubiquitin found in Alzheimer's disease causes neuritic beading of mitochondria in association with neuronal degeneration. Cell Death Differ 10:1721-1732.

Tanzi RE, Bertram L (2005) Twenty years of the Alzheimer's disease amyloid hypothesis: a genetic perspective. Cell 120:545-555.

Terry RD, Peck A, DeTeresa R, Schechter R, Horoupian DS (1981) Some morphometric aspects of the brain in senile dementia of the Alzheimer type. Ann Neurol 10:184-192.

Tun H, Marlow L, Pinnix I, Kinsey R, Sambamurti K (2002) Lipid rafts play an important role in $\mathrm{A} \beta$ biogenesis by regulating the $\beta$-secretase pathway. J Mol Neurosci 19:31-35.

van Leeuwen FW, de Kleijn DP, van den Hurk HH, Neubauer A, Sonnemans MA, Sluijs JA, Köycü S, Ramdjielal RD, Salehi A, Martens GJ, Grosveld FG, Peter J, Burbach H, Hol EM (1998) Frameshift mutants of $\beta$ amyloid precursor protein and ubiquitin-B in Alzheimer's and Down patients. Science 279:242-247.

Vassar R, Bennett BD, Babu-Khan S, Kahn S, Mendiaz EA, Denis P, Teplow DB, Ross S, Amarante P, Loeloff R, Luo Y, Fisher S, Fuller J, Edenson S, Lile J, Jarosinski MA, Biere AL, Curran E, Burgess T, Louis JC, Collins F, Treanor J, Rogers G, Citron M (1999) Beta-secretase cleavage of Alzheimer's amyloid precursor protein by the transmembrane aspartic protease BACE. Science 286:735-741.

Wang C, Gale M Jr, Keller BC, Huang H, Brown MS, Goldstein JL, Ye J (2005) Identification of FBL2 as a geranylgeranylated cellular protein required for Hepatitis C virus RNA replication. Mol Cell 18:425-434.

Willuweit A, Velden J, Godemann R, Manook A, Jetzek F, Tintrup H, Kauselmann G, Zevnik B, Henriksen G, Drzezga A, Pohlner J, Schoor M, Kemp JA, von der Kammer H (2009) Early-onset and robust amyloid pathology in a new homozygous mouse models of Alzheimer's diseases. PLoS One 4:e7931.

Wolfe BL, Marchese A, Trejo J (2007) Ubiquitination differentially regulates clathrin-dependent internalization of protease-activated receptor-1. J Cell Biol 177:905-916. 